\title{
The Status of Research and Innovation on Heating and Cooling Networks as Smart Energy Systems within Horizon 2020
}

\author{
Costanza Saletti ${ }^{1, *(\mathbb{D},}$, Mirko Morini ${ }^{1,2} \mathbb{D}$ and Agostino Gambarotta ${ }^{1,2}$ (D) \\ 1 Department of Engineering and Architecture, University of Parma, Parco Area delle Scienze 181/A, \\ 43124 Parma, Italy; mirko.morini@unipr.it (M.M.); agostino.gambarotta@unipr.it (A.G.) \\ 2 Center for Energy and Environment (CIDEA), University of Parma, Parco Area delle Scienze 42, \\ 43124 Parma, Italy \\ * Correspondence: costanza.saletti@unipr.it; Tel.: +39-0521-905869
}

Received: 28 April 2020; Accepted: 29 May 2020; Published: 3 June 2020

\begin{abstract}
The European Union is funding scientific research through the Horizon 2020 Framework Programme. Since the key priorities for the next few decades are the reduction in carbon emissions and the enhancement of energy system conversion efficiency, a collection of the most recent research projects can be beneficial to researchers and stakeholders who want to easily access and identify recent innovation in the energy sector. This paper proposes an overview of the Horizon 2020 projects on smart distributed energy systems, with particular focus on heating and cooling networks and their efficient management and control. The characteristics of the selected projects are summarized, and the relevant features, including the energy vectors involved, main applications and expected outputs are reported and analyzed. The resulting framework fosters the deployment of digital technologies and software platforms to achieve smart and optimized energy systems.
\end{abstract}

Keywords: European research projects; horizon 2020; digitalization; smart district heating and cooling networks; energy efficiency; intelligent management and control; optimization

\section{Introduction}

Over the last couple of decades, the attention on the anthropogenic impact on the environment has increased and research and actions aimed for sustainable development and climate change mitigation have become widespread [1]. In this context, the European energy scenario has been subjected to a progressive transformation from fossil-based to sustainable and renewable-based systems [2]. According to Bertelsen and Mathiesen [3], the most significant consumer of energy is the heating and cooling sector making up nearly $50 \%$ of the total primary energy consumption in Europe. Many areas with high population density still adopt individual thermal energy production sources that are powered by fossil fuel in $70 \%$ of residential end-users. Hence, there is a relevant potential for decarbonization and improvement in the air quality offered by options that have still not been fully exploited, such as district heating and cooling networks (DHC) and energy efficiency in buildings.

A more rational use of energy can be achieved if the concept of smart energy systems, as defined by Lund et al. [4], is considered. According to the latest accepted meaning, it consists of a holistic approach that integrates the energy sectors and infrastructures (e.g., electricity, heating and cooling, and natural gas), and identifies optimal solutions by benefitting from their synergies and interconnections. This can lead the way to sustainable and renewable future energy systems but also adds new challenges to the existing issues deriving from the integration of discontinuous and distributed resources into the current infrastructure. Indeed, smart energy systems are more complex and, for this reason, their design, management, and optimization require innovative methods and models. In this regard, the novel 
instruments for digitalization and modern technologies such as the Internet-of-Things (IoT) can be exploited to address this complexity and make energy systems smarter [5]. For instance, the availability of large datasets of energy consumption, demand and operating parameters can be advantageous in the development of predictive models and optimal strategies to reduce the impact of energy use on the environment.

These topics are at the forefront of scientific and technological research, but the state-of-the-art context is still fragmented and constantly evolving. Most review reports regarding the transformation of the energy sector take into consideration only the scientific papers submitted to journals and/or conference proceedings [6,7]. These analyses hardly include the research and innovation projects funded by national and international agencies and institutions. Alternatively, other reviews mainly focus on specific aspects such as the forecasting of energy consumption in buildings by means of data-driven approaches based on neural networks [8]; the optimization of energy exploitation in the transportation sector [9]; and the control architectures and management strategies for smart grids [10]. A descriptive summary of support activities from the European Union (EU) on energy efficiency in heating and cooling was published in 2016 [11], but it should be further updated. Another report from the Low Carbon Energy Observatory [12] gives suggestions for research priorities by comparing the objectives of national and international projects.

The scope of this paper is to provide a comprehensive overview of the research and innovation projects funded by the EU as part of the Horizon 2020 Framework Programme. The focus of the study is heating and cooling distribution networks, which are regarded as highly promising in improving air quality and environmental conditions especially in urban areas, within the context of smart energy systems. Special attention is paid to the inclusion of smart management and control strategies, since they are paramount to achieving the digitalization and interconnection of the energy networks. The most relevant projects are reviewed, catalogued and analyzed according to their goals, outputs and characteristics. A summary of such work actions can be helpful for researchers and practitioners in the energy sector for several reasons:

- to summarize the most recent innovations from the point of view of original research, as a result of the cooperation of partners from different countries and realities (e.g., research organizations, companies, and public bodies);

- to explore the potential of public engagement (i.e., participation of the public in energy-related research [13]), usually not included in technical papers, in the identification of technical solutions that are more attractive for customers;

- to keep track of the most recent practical research applications, since international projects often propose the demonstration of technologies in operative environments up to market uptake;

- to provide an overview of the results obtained by coupling scientific research and industrial development;

- to identify the research gaps partially addressed or not yet considered;

- to understand the direction of the global interest and to locate (i) future funding opportunities and (ii) profitable collaborations for addressing new challenges in the energy sector.

\section{The Current European Context}

This section aims to summarize the current framework of the research and innovation projects funded by the European Union. Firstly, it outlines European policy over the past few decades, which aims to promote the transition toward a better society by funding research in key fields, such as the energy sector. Secondly, it lists the main findings of the projects concerning the transition toward a smart energy scenario that have already been concluded as part of the previous funding programme. Finally, the objectives and key information of the latest major funding programme are described in order to give a full picture of the context into which this review is integrated. 


\subsection{European Policy for Research and Innvation}

The Energy Challenge is universally recognized as one of the key priorities to be addressed in the present and future, in order to reduce carbon emissions and mitigate climate change. Since 2007, the European Commission has set fundamental targets. The first step was the adoption of the Strategic Energy Technology Plan (SET-Plan) in 2008 [14]. This document is the principal decision-making support tool for energy technology policies in the EU and aims to accelerate the transition toward a low-carbon and sustainable energy scenario. The first key goals established by the SET-Plan for 2020 were the well-known 20-20-20 goals:

- a $20 \%$ reduction in carbon dioxide emissions;

- a $20 \%$ share of energy from renewable energy resources;

- a $20 \%$ improvement in energy efficiency by reducing primary energy consumption.

Over the past few years, with the target year of 2020 approaching, the progress has been monitored and the strategies have been updated. This resulted in the Clean Energy for All European package [15] which establishes more ambitious objectives for the Energy Challenge up to 2030:

- the renewable energy target is set to $32 \%$;

- the energy efficiency target is increased to $32.5 \%$.

A more long-term goal of the SET-Plan is to limit the rise in temperature of the planet (as an effect of global warming) to no more than $2{ }^{\circ} \mathrm{C}$ before 2050, and also to reduce EU greenhouse gas emissions to between $80 \%$ and $95 \%$ [16]. These are essential in order to fulfill the Paris Agreement of the United Nations Framework Convention on Climate Change held in 2015 [17]. All these measures highlight the importance that the European Union authorities have recently given to research in the energy field through funding opportunities.

In general, all scientific disciplines are addressed by the Framework Programmes (FPs), which are the main financial tools of the EU for providing support to research activities. The fundamental objectives of these opportunities are (i) to link research institutions (e.g., academia and research centers) and industrial research; (ii) to create networks for cooperation and promoting the exchange of ideas, methodologies and tools; and (iii) to foster the actual application of innovation to all areas of society. Each of the first six FPs, from 1984 to 2006, lasted for a period of five years. The 7th and 8th Programmes, instead, ran for seven years and saw a substantial budget increase. More details on these tools, with a focus on the impact on district energy, are given in in the following sections.

\subsection{Previous Projects}

During the previous Seventh Framework Programme for Research and Technological Development (FP7), for the years 2007 to 2013, some research projects were funded with a focus on DHC as well as smart techniques for its management and control. Since these projects have recently concluded, it is worth mentioning some interesting results from this first set of actions:

(1) The CELSIUS initiative is a collaborative project that gathered the expertise and research from a large partnership to demonstrate innovative solutions for integrated heating and cooling in cities and to accelerate sustainable development. The main output is the Celsius Wiki [18], a web resource launched in 2016 that aims to be a source of knowledge and inspiration for cities and utility companies interested in district heating and cooling networks. The platform provides an overview of strategies for planning energy systems as well as the recent innovations concerning all issues of energy use, from efficient supply to smart system integration.

(2) The Energy IN TIME project aimed to develop a smart energy simulation based control method to reduce energy consumption in non-residential buildings [19]. The main output is a control tool for building energy management systems which is automatically and remotely operated. For this purpose, dynamic simulation building models with predictive models of user behavior 
are integrated with adaptive algorithms for real-time control. The project entirely focused on the end-user side of the energy system. The extension of the method to energy networks could be promising.

(3) The CITYOPT project [20] aimed to create a set of applications and guidelines to make planning, design and operation of energy systems more efficient. The main output is a toolset for the optimization of urban districts comprising a simulation layer (specific for decision support) and a real-time layer, designed for demonstration and monitoring.

(4) The READY project aimed to demonstrate a whole city approach for increasing sustainability and renewables uptake, starting from the retrofitting of buildings to the implementation of information technologies in district energy. For instance, one of the main outputs is a short-term heat load forecasting tool based on machine learning and suitable for large district heating networks [21].

This brief overview describes the preliminary steps to exploit and spread smart multi-source energy systems in European countries. Since more work is required to reach state-of-the-art technologies and the commercialization stage, these topics are central also in the following European funding programme, which is laid out in Section 2.3.

\subsection{The Horizon 2020 Programme}

The EU is currently supporting research through the most recent Framework Programme for Research and Technological Development FP8, known as Horizon 2020. It is the biggest EU Research and Innovation Programme ever started with nearly EUR 80 billion of funding available over 7 years, from 2014 to 2020 [22]. Aligned with the European Union strategy for 2010-2020, Horizon 2020 aims to contribute to the realization of a knowledge- and innovation-driven society and is oriented toward the key priority for 2020: intelligent, sustainable and inclusive growth. The programme is divided into three macro-areas, called "pillars" [23]:

- The "Excellent Science" pillar aims to develop long-term skills for the next generation of science, technology, researchers and innovation. This includes funding for talented individual researchers from the European Research Council (ERC), support for collaborative research on future and emerging technologies, innovative training and career opportunities through the Marie Sklodowska-Curie Actions and development of an integrated European research infrastructure.

- The "Industrial Leadership" pillar aims to accelerate technological development and help smalland medium-sized enterprises (SME) grow into leading companies. The main goals are: support for the development and demonstration of advanced technologies in the fields of Information and Communication Technologies (ICT), nanotechnology, biotechnology and space, as well as access to risk finance.

- The "Societal Challenges" pillar addresses the major issues society is going to face in the near future. Such challenges are related to public health, food security, climate action, intelligent transportation, and "Secure, Clean and Efficient Energy".

The latter has been conceived "to support the transition to a reliable, sustainable and competitive energy system", since it is recognized as one of the major challenges of the near future [13]. The work programmes in Horizon 2020 are biannual in order to allow a better preparation of applicants. Therefore, three major phases can be identified for the "Secure, Clean and Efficient Energy" challenge throughout the duration of the programme:

- Work Programme 2014-2015. This first call for proposals was structured in three specific research areas: "Energy Efficiency" applied to buildings, industry, heating and cooling and their integration with ICT; "Competitive Low-Carbon Energy" such as renewable energy sources; and "Smart Cities and Communities".

- Work Programme 2016-2017. Similarly, the second part contributed to the two focus areas of "Energy Efficiency" and "Competitive Low-Carbon Energy". 
- Work Programme 2018-2020, which was recently published and is currently open for proposals. This call includes the contribution to the focus area "Building a low-carbon, climate resilient future" with special attention paid to energy efficiency and global leadership in renewable energy solutions for implementation at the energy system level.

In particular, increasing attention is given to DHCs, which offer the opportunity to improve the air quality of urban environments by means of (i) the efficient, smart and cheaper distribution of thermal energy and (ii) the integration of multiple resources, including renewables. This is specified, for instance, by two calls for proposals from different work programmes: firstly, the call EE-13-2015 [24] requires to develop the new generation of intelligent heating networks by means of innovative metering, control and optimization tools; secondly, the call LC-SC3-RES-8-2019 [25] supports cost-effective solutions for heating networks with at least a $50 \%$ share of renewable energy sources to be tested in operational environments. A large number of universities, research centers, private companies and public bodies answered these and other calls giving rise to innovative research projects.

In order to have a broader idea of the purpose and methodology of each considered project, it is beneficial to make a further distinction according to the funding scheme adopted within the Horizon 2020 framework:

- Research and Innovation Action (RIA): these actions aim to establish new knowledge and to explore the feasibility of new technologies and solutions. They typically include small-scale development, testing and validation of a prototype in a laboratory or simulation environment.

- Innovation Action (IA): typically guided by industrial partners, these actions aim to improve, demonstrate and validate a state-of-the-art idea on a large scale, in order to show its feasibility and convenience for the market.

- Coordination and Support Action (CSA): these actions primarily consist of accompanying measures and complementary activities that aim to improve the networking and cooperation between programs in different countries. These actions include standardization, dissemination, awareness-raising and communication.

The main difference between the former two funding schemes is the value of the Technology Readiness Level (TRL). The TRL is an indicator that defines the maturity level of a given technology, providing a common understanding of its status and addressing the entire innovation chain. It is based on a scale from 1 to 9: lower values of TRL typically represent basic research or proofs of concept (i.e., RIA), while higher values are indexes of more mature products that approach the status of manufacturing or commercialization (i.e., IA). Figure 1 shows the definitions of the TRLs and their correspondence with the two main funding schemes described above. It is more common for IA to have larger consortia and more industrial subjects in the partnership than RIA. This can be justified by the companies' interest in achieving a product ready to be introduced on the market and by their ability to speed up the demonstration and manufacturing process.

The opportunities within Horizon 2020 outlined above are going to end in 2020. The next FP approved by the EU is named Horizon Europe and is even more ambitious than FP8, with a total funding higher than EUR 100 billion and a similar duration of seven years, from 2021 to 2027 [26]. It is expected to pursue clearly defined targets in five mission areas, including "Climate-neutral and smart cities" [27]. Hence, the research topic targeted in the present work is expected to be at the forefront of innovation also over the next decade. 


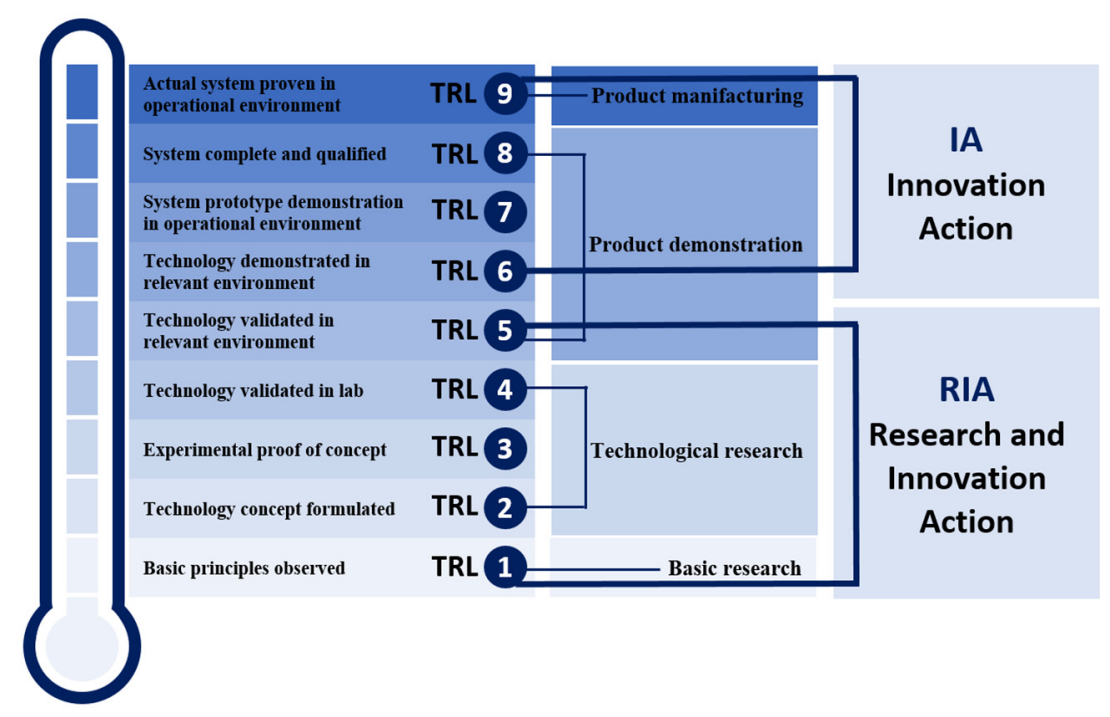

Figure 1. Technology Readiness Level definition.

\section{Research Method}

As stated above, the present study aims to give an overview of the research and innovation projects funded by the Horizon 2020 Programme that are relevant to the "Secure, Clean and Efficient Energy" challenge and, in particular, to smart district energy systems. This can be done by selecting the work actions focused on smart energy, smart grids, digitalization of the energy sector, smart control, and optimization of energy systems and intelligent technologies for districts and buildings.

Nonetheless, the construction of a map of Horizon 2020 projects may be a challenging task, as the projects are often large and involve partners from different countries and backgrounds. Moreover, individual work packages are distributed to different research groups, thus preliminary results and public information may be difficult to find. In addition, some characteristics, methods, or outputs of the projects are not detailed in the general description. Therefore, a constant update of the available information is required to identify their features correctly.

Two recent articles with a similar scope are available in the literature. Moseley [28] highlights and addresses this issue presenting a detailed and comprehensive review of recent and ongoing Horizon 2020 research, innovation and market uptake projects on "smart buildings". Firstly, a definition of the "smartness" of a building is identified as its technological readiness to manage itself efficiently, and to interact with its occupants and the wider energy environment. Keeping these criteria in mind, the author examines the tasks, scopes, and innovations focusing on building automation, demand response, energy management, and ICT interfaces for energy efficiency at building level. The outcome of this paper is a useful summary and comparison of 42 relevant Horizon 2020 actions funded within the calls for proposals of the years 2014, 2015, and 2016. The paper, published in 2017, cannot include the most recent developments of the programme. Moreover, the interactions between the building and the global energy system as well as the potential innovations at district level are excluded, as they are beyond the scope of the paper. On the other hand, Longo et al. [29] present a review of the ongoing and concluded projects that study energy poverty in households and vulnerable consumers from the perspective of energy provision, in order to understand the common framework and future trends to solve this issue in an international context. The work collects 43 relevant projects spanning over the FP7 and Horizon 2020 Programmes. Furthermore, it identifies the most recent calls of 2019 as the turning point in the recognition of energy poverty as an issue to be addressed with specific calls, common specifications, and standardized measures.

These studies are relevant to the considered application field. Nevertheless, they do not involve the energy systems more broadly. In the present context, it is essential to investigate the entire energy system in a holistic way, its interactions and connections, and the innovative methods to improve its 
efficiency. Moreover, with Horizon 2020 coming to an end, a summary of all the funded actions can be of interest. This is proposed, for instance, in [30], which gives a quantitative outline of the European research regarding the concept of Smart Cities.

The present work adopts a method similar to the aforementioned papers, with a focus on the development of smart tools and approaches for heating and cooling energy systems, comprising district level, building level, and their integration with other energy carriers.

Firstly, a close examination of the Community Research and Development Information Service, also known as the CORDIS portal [31], was carried out. This portal is the primary reference for information on every EU-funded project in different programmes and calls over the past two decades. It includes the general description and, when applicable, results in brief for each available project. The search was conducted with the following keywords and their combinations: District Energy; District Heating and Cooling; Smart Energy System; Optimization; Intelligent Control and Management; Predictive Control; Energy Sector Integration; Digitalization. Special attention was paid to projects that involve Model Predictive Control (MPC), as this is a well-known efficient control strategy for chemical and industrial processes but its further application to district energy still has to be explored to a greater extent [32].

The characteristics of the projects selected as relevant to the scope of the paper were scrutinized in depth by referring to the dedicated website. In particular, the analysis focused on the subdivision of the projects in work packages (WPs), on the demonstration case studies—when applicable-and on the published dissemination material (such as deliverables and reports). In some cases, the website contained a section dedicated to the related projects, which share the objectives, applications, or part of the consortium. These were further examined in order to identify and include additional work actions in the analysis that were not obtained during the preliminary search phase. Moreover, science databases were explored for potential publications (e.g., conference or journal papers) from the main research groups involved in the projects, in order to track the preliminary results of the ongoing projects as well as the outcomes of those already concluded.

The material and documentation were collected in a database that can be periodically updated with new information and current results when they become available. Each action was represented by a project profile sheet that gathered the following data:

- $\quad$ name and acronym;

- $\quad$ project website and logo;

- grant agreement and total funding;

- $\quad$ start and end dates of the project activities;

- partnership, divided between private companies, research institutions, universities, public bodies, and others;

- general description and main goals;

- location of the demonstration sites;

- preliminary results and current status.

Regarding the goals and activities carried out or expected, the main features-relevant to the development of smart energy systems-were highlighted for each selected project. These features, detailed in Table 1, include (i) energy vector, (ii) major application, (iii) project output, (iv) purpose and methodologies. This defines a comprehensive research and innovation framework that can be exploited to identify scientific and technological gaps to be considered for future activities. The discussion of this framework is outlined in Section 4.

\section{Results and Discussion}

The search described in Section 3 resulted in 58 work actions funded within all three Work Programmes of Horizon 2020. All the selected projects are relevant to the topics of this search in at least one work package. The general characteristics that identify each project, such as funding scheme, 
total funding amount, coordinator country, and dates, are collected in Table A1, while their relevant features are reported in Table A2, both in Appendix A. The discussion and analysis of both of these aspects are given in the following sections.

\subsection{General Information}

The analysis of the general information of the Horizon 2020 research projects on smart energy systems can improve the understanding of where and when the majority of the funding has been directed. As shown in Figure 2, the coordinators of the projects come from 13 different countries, situated in western or northern Europe, where typically thermal networks are more widespread. The only exception is represented by the TOPAs project, which is coordinated by a private company from Israel. The two most represented countries are Spain and Italy, where the former coordinates 14 projects (almost one quarter of the total) and the latter coordinates 11 projects (about 19\%). The United Kingdom coordinates six projects $(10 \%)$, while participants from France and Belgium are responsible for five $(8.5 \%)$ and Germany for four $(7 \%)$ projects. Sweden, Finland, Denmark, the Netherlands and Austria have two projects each, while Ireland and Israel, cited above, coordinate one of the selected actions each.

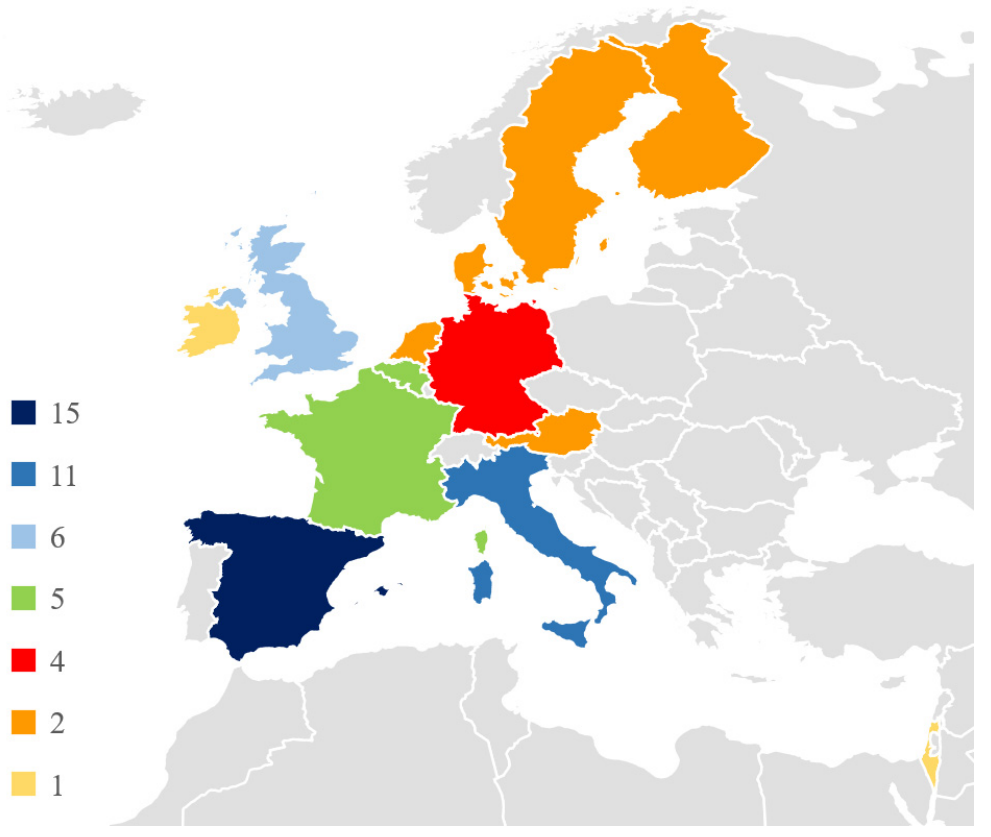

Figure 2. Number of projects per coordinator country.

These considerations are confirmed by Figure 3, which gives a representation of the number of projects that partners from the different countries are contributing to. The most represented country is again Spain, as it participates in almost 70\% of the selected projects (39). Germany and Italy follow with 37 and 35 projects, respectively, while France and Belgium each participate in 30 work actions, and the United Kingdom in 29. Nonetheless, it is possible to notice that the most part of the European countries are involved in studies and demonstration activities on smart energy systems: Denmark and the Netherlands (19), Sweden (17), Austria (15), Ireland (14), Switzerland (13), Poland (12), Greece (11), Finland and Czech Republic (10 each), Croatia (9), Romania (8), Serbia (7), Slovenia and Portugal (6 each), Hungary, Bulgaria, Cyprus, and Turkey (4 each), Norway, Estonia and Latvia (3 each), Lithuania, Luxembourg, and Bosnia-Herzegovina (2 each), and North Macedonia and Ukraine (1 each). Furthermore, there is the contribution of Israeli partners in three projects and Indian partners in one project. The latter is not shown in Figure 3 for clarity. 
Table 1. Features for the selection of the research and innovation projects that involve smart energy systems.

\begin{tabular}{|c|c|c|}
\hline \multicolumn{2}{|c|}{ Feature } & Explanation \\
\hline \multicolumn{2}{|c|}{ Energy vector } & This identifies the energy carriers the project works on: thermal power, cooling power, electricity, or natural gas. \\
\hline \multirow{2}{*}{ Application } & Grid/District & The project's activities are applied at grid or district level, generally involving a multi-source complex energy system. \\
\hline & Building & The project's activities are applied at building level. \\
\hline \multirow{4}{*}{ Main Outcome } & Software/Platform & The scope of the activity is to create a software package, a platform, a web application, or a framework for researchers and industries. \\
\hline & Model/Library & The scope of the activity is to create a model or a library of models for the effective simulation of buildings or district energy system components. \\
\hline & Optimization tool & $\begin{array}{l}\text { The activity comprises the development of an optimization algorithm or the solution of optimization problems for minimizing an objective } \\
\text { (e.g., cost, total energy consumption). }\end{array}$ \\
\hline & Business model & The activity aims to create a new business model for the industrialization or exploitation of the concept. \\
\hline \multirow{7}{*}{ Purpose } & Planning & The purpose of the project is to perform long-term (yearly) planning and scheduling of the system. \\
\hline & Sizing/Design & The sizing or design of the distribution grid, generation systems and loads, additionally considering the topology, are carried out. \\
\hline & Retrofitting & The purpose of the project is the evaluation of adding innovative technology to existing systems for refurbishment. \\
\hline & Real-time control & Innovative intelligent control strategies are implemented and tested. \\
\hline & Monitor/Management & System monitoring through smart meters and sensors and overall system management to achieve a given goal is performed. \\
\hline & Diagnosis & The methodology is developed to perform system diagnosis or fault detection. \\
\hline & MPC & $\begin{array}{c}\text { The Model Predictive Control technique is applied: the control action is optimized based on the future behavior of the system predicted by } \\
\text { a dynamic model. }\end{array}$ \\
\hline \multirow{7}{*}{ Other } & Machine learning & $\begin{array}{l}\text { Machine Learning and Artificial Intelligence techniques are used for the classification and identification of models by exploiting the available } \\
\text { data on the system. }\end{array}$ \\
\hline & Forecasting & The forecasting of weather conditions, energy demand or other external disturbances are implemented. \\
\hline & LCA/LCC & Life Cycle Analysis or Life Cycle Cost are performed to evaluate the global environmental or economic impact of the system. \\
\hline & Demand Response & $\begin{array}{c}\text { Demand Response strategies are integrated in order to adjust energy demand to match the supply through engaging customers and promoting } \\
\text { behavior that is beneficial to the system. }\end{array}$ \\
\hline & Peak shaving & Strategies for the elimination or leveling of the peak loads are evaluated. \\
\hline & Storage & Energy storage is accounted as a key component to improve the flexibility of the system. \\
\hline & RES & There is specific reference to the integration of Renewable Energy Sources (RES) as one of the goals of a work package. \\
\hline
\end{tabular}


As far as the distribution of the projects over time is concerned, Figure $4 a, b$ show the number of actions per start year and end year, respectively. Almost all the projects (i.e., $85 \%$ ) considered relevant to this analysis started from 2015 to 2017, while only eight started in 2018 and 2019. This is also due to the fact that recently started projects are still in the preliminary phases and do not yet have reports or, in some cases, a website. Therefore, the periodic update of the project database is a way to include more actions and improve the results of this analysis with new available knowledge. On the other hand, almost $70 \%$ of the projects are still ongoing, while the remaining 30\% concluded their research in 2017 (1), in 2018 (5) and more recently in 2019 (12). This indicates that, during the next few years, an increase is likely to be seen in publications and reports once the results from the demonstration of the proposed new technologies are available.

It is also interesting to analyze the distribution of the projects depending on the funding schemes cited in Section 2.3, in order to give an estimation of the maturity level that these technologies are expected to reach. According to Figure 5, only seven projects, equal to $12 \%$ of the total, are Coordination and Support Actions. The most part of the selected projects are instead IA or RIA with the former equivalent to $52 \%$ (30) and the latter to $36 \%$ (21). This distribution shows that the available funding for smart energy systems is mostly dedicated to technologies demonstrated at least in a relevant or operative environment (TRL 6 or 7, with reference to Figure 1).

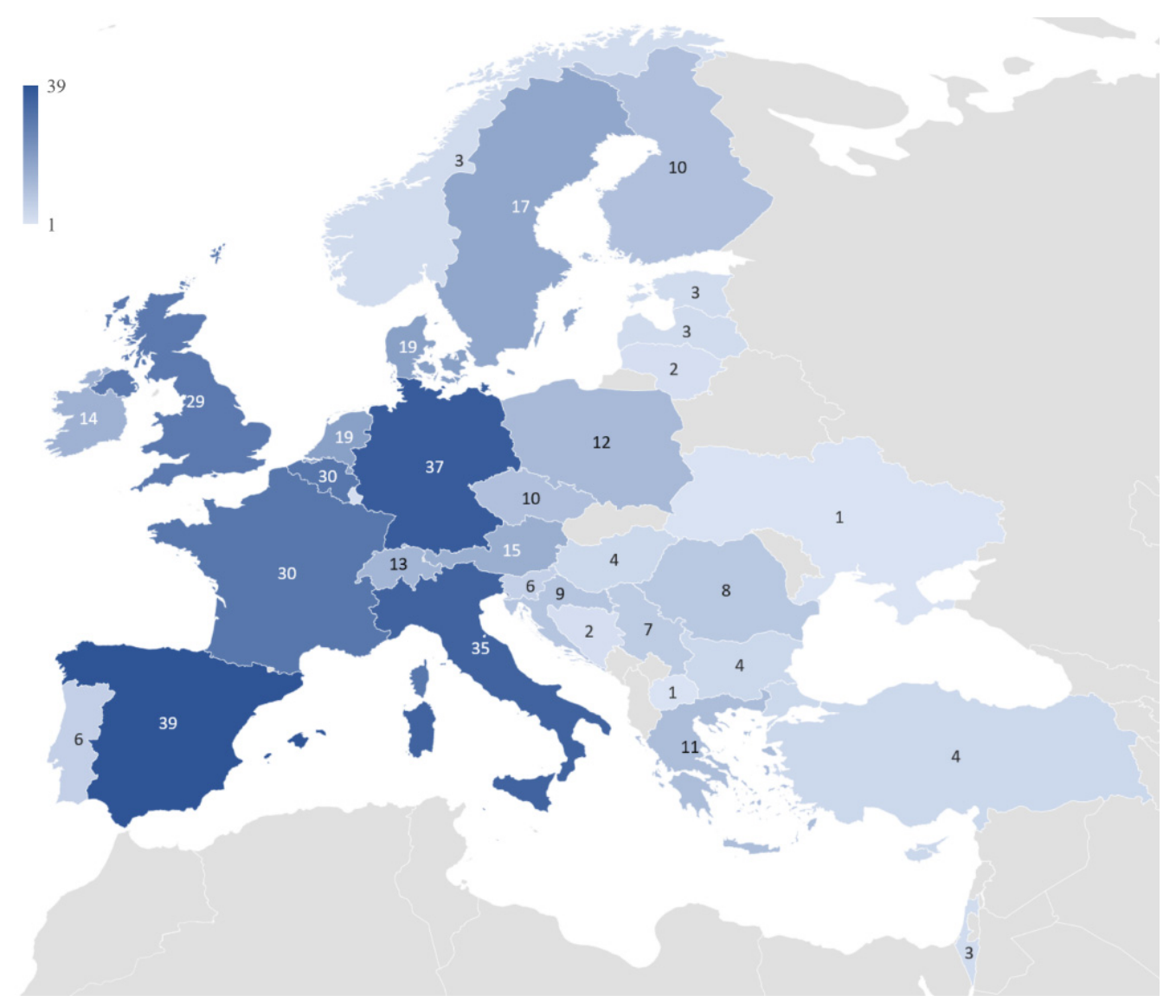

Figure 3. Number of projects per participating country. In addition, India participates in one project (not shown). 


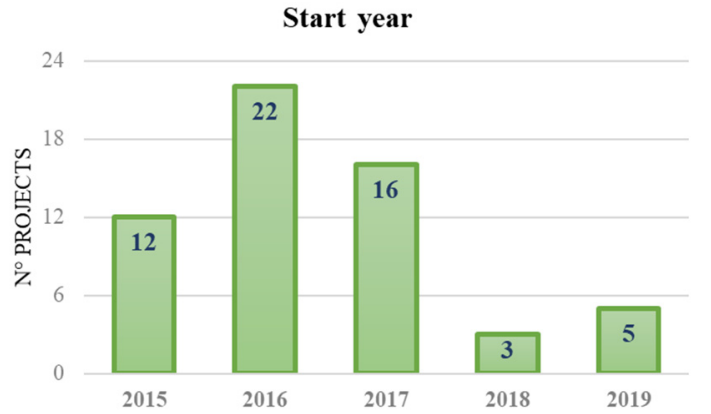

(a)

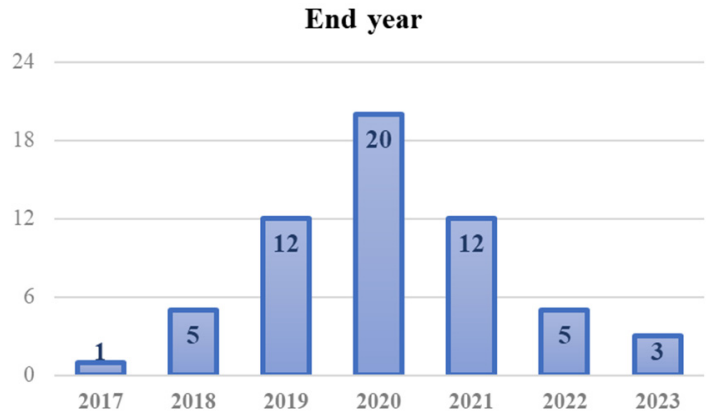

(b)

Figure 4. Number of projects per (a) start year and (b) end year.

This is of key importance since the spread of smart and integrated energy networks throughout Europe is possible if innovative technologies, once demonstrated, become available at a commercial level. Nonetheless, feasibility studies and testing in laboratory (TRL 1 to 5, as in Figure 1) are also considered relevant to allow new concepts to be proposed and, potentially, further carried out in future actions. In this regard, an interesting case is that of the STORM project, followed by the TEMPO project, both coordinated by the same institution. The former is an RIA and developed a smart controller for district heating and cooling with the features of load forecasting and thermal peak shaving [33]. The latter is an IA aimed to extend the functionalities of the STORM controller and bring it forward in the path toward market readiness.

\section{Funding scheme}

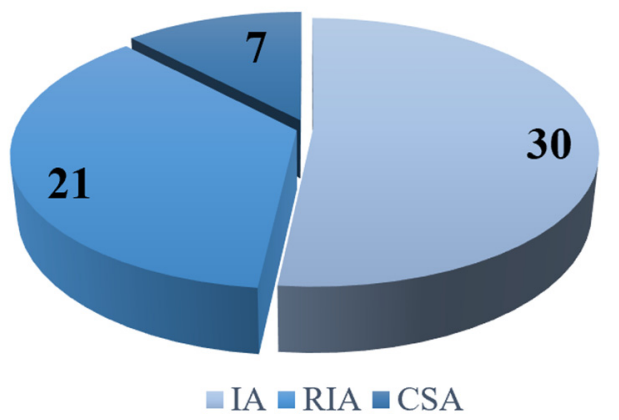

Figure 5. Number of projects per funding scheme: IA Innovation Action; RIA Research and Innovation Action; CSA Coordination and Support Action.

\subsection{Project Features}

After summarizing the general characteristics of the selected work actions, it is important to analyze their specific features (with reference to Tables 1 and A2) in order to outline the outcomes and improvements expected in the coming years, and to understand the methods that should be further explored.

Figure 6a represents the number of projects that explicitly consider heating, cooling, electricity, or gas, or a combination of these, as energy vectors. Since the analysis is mainly dedicated to smart thermal networks, the most exploited vector is heating which is combined with cooling technologies in 20 projects. In general, district heating is more widespread than district cooling. This is confirmed by the fact that, out of the selected projects, only INDIGO [34] is entirely aimed to improve planning, control and management of a district cooling network. Only three projects are fully dedicated to smart methods and technologies for the electric grid, while 22 projects integrate electricity with thermal vectors. Overall, six actions attempt to tackle a global urban energy system by exploiting the synergies between heating, cooling, electricity, and natural gas at the same time. These are promising steps 
toward the development of an efficient "network of networks", in which sector integration allows the energy to be stored and converted into the most convenient form, depending on the external conditions. However, this should be further explored with more research and demonstration activities.

Figure $6 \mathrm{~b}$ depicts the distribution of the projects depending on their main application. As expected, most works focus on the districts (26), while fewer develop technologies that are applied to single buildings (12). Nonetheless, 20 projects integrate the building level with the district level, showing a significant interest in providing methods that can be implemented to an energy system in its entirety, from energy conversion to end-user supply.

The analysis of the main outcomes and purpose of the projects is depicted in Figure 7a,b, respectively. More than half of them (33) aim to build a software package, a web platform, or an application that can efficiently help researchers and stakeholders increase knowledge on complex energy systems. This shows the trend toward the digitalization of the sector, in opposition to the conventional approaches typically based on the experience of the system operators. The development of models or a library of models that can accurately simulate the behavior of energy systems is another important aspect that is proposed by 21 projects. These models can also be used to promote the future exploitation of the technologies, allowing them to be evaluated and replicated to systems other than the project demonstrations sites. Likewise, optimization algorithms with the scope of minimizing energy consumption or cost are implemented in 24 work actions.

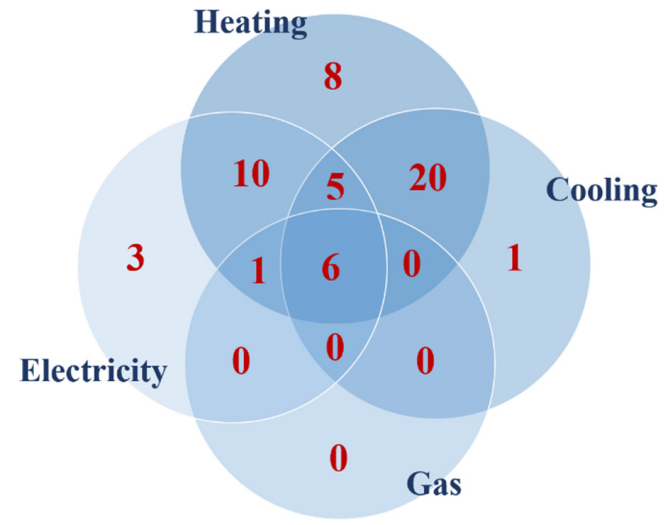

(a)

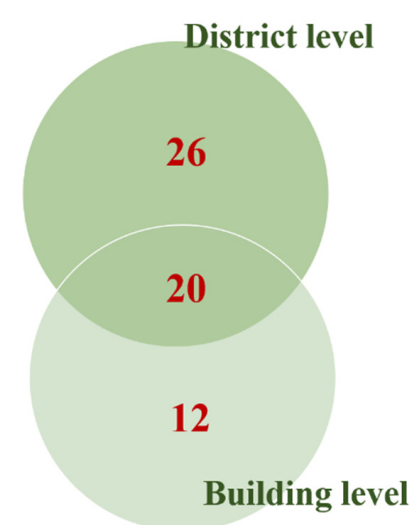

(b)

Figure 6. Number of projects per (a) energy vectors involved (b) and main application.

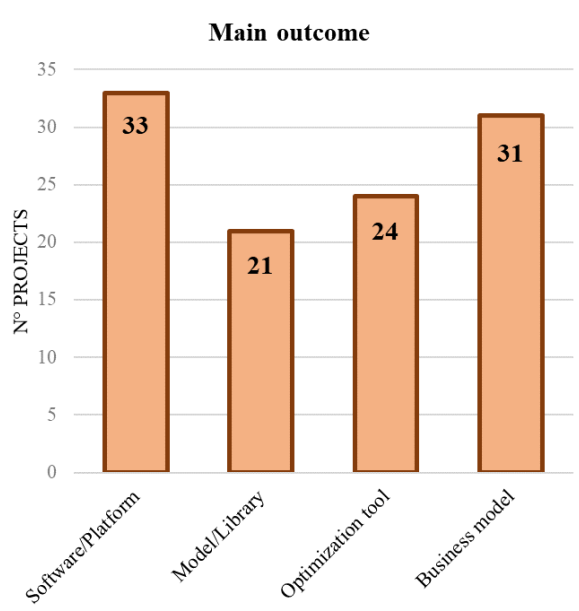

(a)

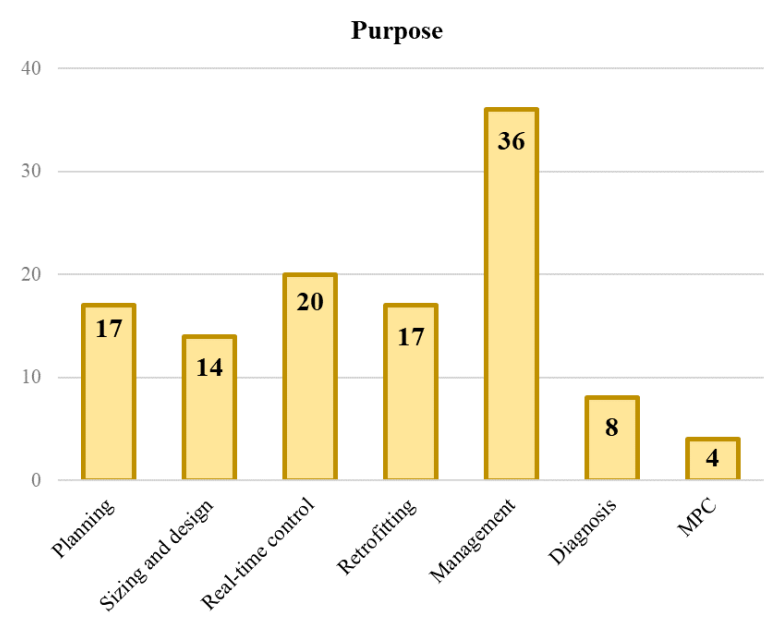

(b)

Figure 7. Number of projects per (a) main outcome and (b) principal purpose of the study. The detailed explanation of the features is reported in Table 1. 
Lastly, the importance of tackling smart energy networks not only with reference to technical and engineering issues, but also from an economic point of view is shown by the large number of projects that include the creation of new business models for the actual market evaluation of smart technologies. Indeed, a ready business model is paramount to (i) make them attractive to investors, consumers, and stakeholders in general and (ii) foster the increase in TRL.

As can be seen from the outlook on the project features in Table A2, the selected work actions hardly focus on a single target, as a multi-stage and multi-disciplinary approach is fundamental for making energy networks smart. System management or monitoring with sensors, in order to obtain real-time data for digitalization, is achieved by more than $60 \%$ of the projects (36). In 20 projects, one of the main goals is the development or testing of a smart real-time control strategy, which shows the importance of system control in improving efficiency. However, predictive controllers (i.e., MPC) are only proposed in four cases. The production planning (e.g., day-ahead scheduling or load allocation) of multi-source energy networks and the retrofitting of existing systems, typically buildings, are both achieved by 17 projects, while the development of efficient methodologies for designing or sizing new systems in an optimal way is the purpose of 14 work actions. A limited number of projects (8) focuses on diagnosis and fault detection. Understanding the most common faults in district heating networks and adopting the right approaches to overcome them, however, can help decrease the operating temperatures and, therefore, increase system efficiency, as shown for instance by the TEMPO consortium [35].

The additional features analyzed in this work can be of particular significance as they all represent innovations for energy systems. The number of projects tackling such features is shown in Figure 8. As expected, more than $70 \%$ (42 out of 58) of the selected projects contemplates explicit goals, work packages, or activities for the integration and efficient management of RES in the energy systems. This is essential for the development of the new generation of DHC [2] and smart energy systems [4], for which the combination of waste heat recovery and alternative sources is required. Another key element is the integration of storage technologies to decouple supply and demand (as they are seldom simultaneous) and to increase the flexibility of the system by scheduling production when it is more convenient from an energy consumption or cost perspective. This is tackled by 21 actions $(36 \%)$. The exploitation of IoT and machine learning technologies is carried out by 18 projects, typically to perform load forecasting (14 projects), which is highly influenced by the external conditions. This is essential especially in thermal networks, where the dynamic behavior is slower compared to the power grid. For this reason, an energy efficient production has to be planned in advance in order to correctly answer the load variations. On the other hand, network flexibility can also be enabled on the consumer side by promoting Demand Response (DR), i.e., shaping the demand of the end-users to match the optimal management of the network. This can be proposed for any energy carrier involved in the energy system. The DRIvE project [36], as well as seven other research projects, study DR technologies that are feasible when advanced ICT platforms, optimization algorithms, and real-time control architectures are implemented [37].

Fewer works perform LCA studies (six work actions) involving future scenario analyses with a long-term perspective. Only three projects implement thermal peak shaving, which has the ability of reducing the fluctuation of thermal demand and, therefore, achieving a more stable operation of the production plants (e.g., potentially avoiding the frequent start-up of auxiliary equipment). For this reason, it should be more widely addressed in future funding opportunities.

All the projects and features analyzed in the present paper are finally collected together in the interconnection map depicted in Figure 9, similarly to [12]. 


\section{Other features}

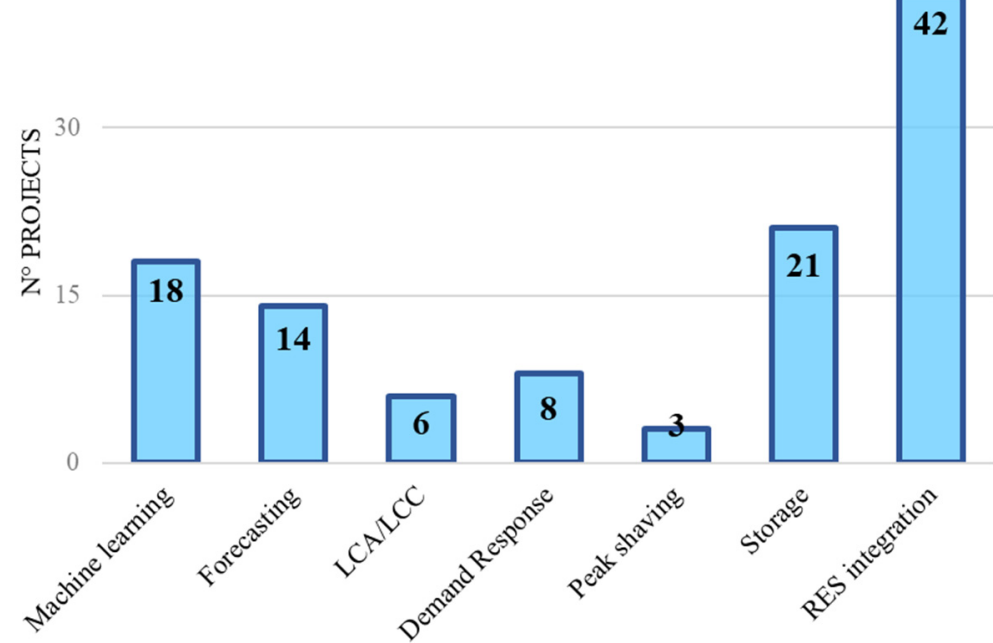

Figure 8. Number of projects per other features included in the project activities. The detailed explanation of the features is reported in Table 1.

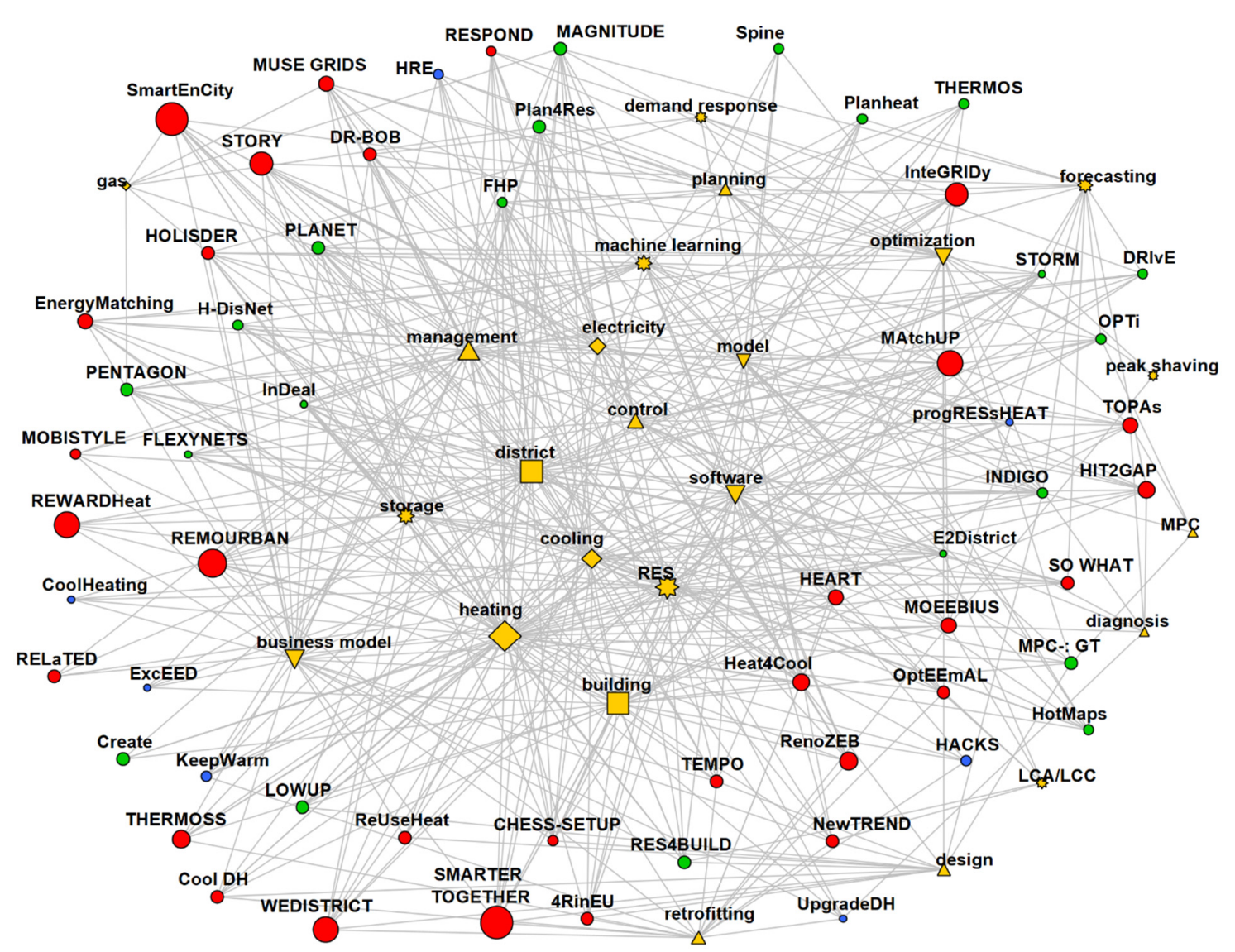

Figure 9. Interconnections between the selected projects and their relevant features. The circles represent the projects (red for IA, green for RIA, blue for CSA), with the size proportional to the funding amount. The yellow symbols represent the features, with the size proportional to the number of interconnections with the projects. The detailed explanation of the features is reported in Table 1.

The circles correspond to the selected Horizon 2020 projects with the diameter proportional to the amount of funding (with reference to the data collected in Table A1). The color of the circle indicates 
the type of funding scheme, where red, green and blue stand for IA, RIA and CSA, respectively. Each project is linked to the involved features, represented by the yellow symbols. The shape of the symbols corresponds to a different feature category with reference to Table 1 (i.e., diamond for energy vector, square for application, inverted triangle for main outcome, triangle for purpose and star for other features). The size of each symbol is proportional to the number of interconnections and, consequently, to the number of projects that directly tackle the feature. The largest cluster of characteristics include heating applications at district and building level by means of software packages, simulation models, and business models, with the purpose of smart management and control, often involving machine learning and RES integration. Since they are key issues of smart DHCs, this is coherent with the scope of this work. Promising features such as demand response, peak shaving, MPC, and fault detection for heating networks are on the edges of the map and deserve future in-depth analysis. It also emerges from the graph that the projects with the largest budgets, in some cases higher than EUR 10 million, are all IA and involve technology demonstration on a large scale.

The comparative analysis outlined in this section resulted in some final thematic considerations concerning the real-time control of the system. Apart from the already cited STORM project [33], other interesting outputs are as follows:

- the INDIGO project develops an MPC for the generation, distribution and consumption levels of district cooling systems and provides a library of models for detailed information on the physical phenomena occurring in the components [38];

- the OPTi project [39] proposes an integrated toolset for user-centric optimization of DHCs, adopting the MPC strategy and advanced modeling techniques;

- the TOPAs project designs centralized and distributed MPCs suitable for controlling the temperature in separate areas of single building environments, and compares the related performances [40];

- the FLEXYNETS project [41] aims to test different control strategies by means of a small-scale experimental test rig that emulates a real thermal network;

- the E2District project deploys a novel management framework for district heating systems with a large number of tools and the aim of lowering the distribution temperature [42].

\subsection{Other Projects}

In the framework of the international funding opportunities, the ERA-Net Cofund scheme [43] can be of further interest for the deployment of smart energy systems. Indeed, 32 transnational projects were funded under the Smart Grids (SG+) Joint Calls from 2015 to 2017 while 23 other actions were funded under the Smart Energy Systems (SES) Joint Call in 2018 [44].

These calls have the prerequisite that the funded actions adopt the three-layer model, consisting of three categories-i.e., stakeholders, market and technology — to be integrated in the smart grid/energy environment. As a matter of fact, the interrelation and combination of these three layers can improve the assessment and uptake of smart energy systems [45]. In particular, it is recommended to tackle the problems from a multidisciplinary point of view, by coupling market analysis, social acceptance and consumer need with the technical aspects.

The first calls were more focused on the power grid, as shown for instance by the ReFlex project, which developed use-cases for flexibility in smart grids and published a guidebook for their replication [46]. In the following opportunities, heating networks and sector coupling are becoming more attractive. The DISTRHEAT project, funded as part of the call in 2018, aims to develop a scalable predictive controller for DHCs suitable for fast replication at any scale, from an individual building to a city network [47].

Thus, despite the smaller partnerships and budgets involved in these actions, these calls should not be underestimated since they fund research on specific topics of the energy sector, and promote multidisciplinary evaluation and testing. Furthermore, the ERA-Net SES Initiative 
promotes communication and networking between different project partnerships by organizing conferences, webinars and follow-ups. This aims to create a broad network of institutions, companies and other participants engaged in the field of smart energy systems.

\subsection{Drivers and Guidelines}

The overview outlined above is a comprehensive picture of the current status of research and innovation projects. This section provides some general indications and guidelines for future developments that can be derived from these results.

Firstly, it is possible to identify some key features that should drive research and innovation on smart DHCs:

- Digitalization. The worldwide context has evolved toward an interconnected and data-driven system, dominated by more efficient tools and devices from the ICT world as well as by data mining and machine learning techniques. This creates opportunities also for the energy sector, which can benefit from these new technologies in order to achieve more sustainable energy systems by means of the smart management of low-carbon sources (e.g., renewables and waste heat) and predictive maintenance. In this regard, one of the greatest potentialities is offered by real-time optimal control methods, which require online data processing and computationally efficient algorithms. While they were not applicable in the past, nowadays they are enabled by the latest developments in programmable controllers, innovative software and hardware architectures. These methods reinforce physics-based system modeling, which is in any case essential in accurately representing the occurring phenomena and understanding the system behavior. Overall, digitalization is beneficial for smart energy systems and should be pursued by means of the synergic match between physics-based representation, available data, and software.

- Integration. The most part of the projects summarized in this paper involves only one or two energy domains. The integration of all energy vectors (i.e., electricity, heating, cooling, natural gas), on the other hand, allows synergies to arise between these domains. Indeed, the conversion of energy into the form that is most cost-effective or energy-efficient for the global system (depending on the actual boundary conditions) will lead to optimal exploitation of renewables and energy saving. It is paramount to invest and research on enabling technologies, such as energy conversion devices (e.g., Power-to-Gas and Power-to-Heat) and optimal ways to control their integration. Furthermore, the integration should be seen also from a social point of view, as positive interactions between producers, consumers, networks and infrastructures could improve the management of smart energy grids.

- Decarbonization, toward a $100 \%$ renewable energy system that requires storage technologies to be strongly implemented. When dealing with energy storage, it is necessary to focus not only on proper storage devices, but also on unconventional storage concepts, e.g., building envelopes, frozen food, and controllable load in industry.

- Last, but not least, resilience, which is currently of utmost relevance due to the COVID-19 containment measures that have greatly affected the energy scenario and that may have repercussions in future years [48]. Similarly, the global energy system will have to be able to adapt to other unpredictable global events that might occur in the future.

All these trends have already been identified as strategic lines for the Horizon Europe programme. Finally, it is also possible to delineate some general guidelines aimed to assist specific actors of the energy sector in future research and innovation:

- Policy makers, who are responsible for defining the priorities for the next calls [16], shaping funding opportunities and updating roadmaps [49-51]. The prospect of smart approaches and available renewable technologies is vast, but most are still at a preliminary phase. In the light of this, policy makers and investors should stimulate the work actions that demonstrate the feasibility of these technologies in operational environment (i.e., IA). They should also promote the formation 
of experimental areas where more smart technologies can be integrated, tested and exploited jointly [52], and where limitations (e.g., due to interferences between different technologies) and opportunities (e.g., due to synergies between technologies) can be observed. Overall, the leading trend for the next few years is to rely on strong and well-defined partnerships in order to actualize innovation. Another fundamental aspect that should be included in future opportunities is social and economic research. As a matter of fact, the spread of digital technologies might be limited by opposition from consumers. Hence, investigating social acceptance, accessibility and affordability, as well as creating new business and behavioral models in order to engage the customers in innovation, will determine win-win solutions for consumers, producers, network providers and investors.

- Energy system designers, who should adopt an integrated holistic approach to system development. Indeed, they should focus on the optimization of the entire energy system (also with LCA and evaluation of the environmental performance in the long term) and not of individual components, by considering design and operation at the same time with the help of system digital twins and simulation platforms. The designers should also consider the limitations (e.g., the current power grid capacity) and opportunities (e.g., increasing the share of renewables and waste heat recovery) given by the evolution of the energy context. It is important to propose solutions with high potential for replication, but also to adapt and exploit the new tools made available by research and innovation in order to retrofit the existing systems.

- Researchers, who should deeply investigate the applicability of digital technologies in theory and practice. It is paramount to move from technological research to product demonstration in relevant and operational environments, in order to bring innovation to the market. One of the key priorities is to develop new interactive platforms for decision-making, energy network management and cross-sector integration. It is also important to focus on methods which, in the presented projects, have not been addressed to a significant extent. Real-time control is still raw and outdated in most DHCs, therefore the implementation of MPC strategies, enabled by new developments in ICT and optimization, deserves more attention. Other promising approaches include peak shaving and demand response, which should be exported to thermal networks. Finally, researchers should not underestimate social and economic research in order to cover user needs and involve the end-users in identifying more profitable solutions.

\section{Conclusions}

This paper proposes an overview of the most recent research projects, funded by the European Union within the Horizon 2020 Framework Programme, with the aim of making district energy systems smarter. An in-depth search of the CORDIS portal, the database of the European Union projects, followed by the analysis of websites, reports and publications resulted in the selection of 58 relevant work actions. The general information and specific features regarding energy vectors, applications, and outcomes were collected in detailed tables. Special regard was given to the projects involving the optimization, control and management of district heating and cooling networks. The analysis of the data made it possible to draw quantitative and qualitative considerations from the selected Horizon 2020 work actions as follows:

- the projects on smart energy systems are mainly coordinated by partners in western and northern Europe, even though almost every European country contributes to the innovation;

- it is reasonable to expect a large number of publications and data available from technology demonstration, as most of the projects are still ongoing;

- there is increased interest in the integration of electricity, heating, cooling, and natural gas sectors, in order to exploit their synergies and interconnection/storage technologies in an optimal way;

- similarly, about one third of the projects tackles both district and building levels, considering the system from production to consumption; 
- $\quad$ software applications with model libraries, digital technologies, and business models are key elements of the future smart energy systems;

- a few projects that address real-time control obtained promising results from predictive control strategies, which deserve further testing;

- additional funding opportunities such as the ERA-Net Smart Energy Systems Joint Calls are regarded as relevant since they foster sector integration and the inclusion of social and economic aspects in innovation.

Overall, this framework establishes a starting point for the evaluation of future technologies, research gaps and funding opportunities within the next Horizon Europe research and innovation programme.

Author Contributions: Conceptualization, M.M.; methodology, C.S. and M.M.; investigation, C.S.; data curation, C.S.; writing — original draft preparation, C.S.; writing—review and editing, C.S., M.M., and A.G.; visualization, C.S.; supervision, A.G. and M.M.; project administration, M.M.; funding acquisition, M.M. All authors have read and agreed to the published version of the manuscript.

Funding: This research was performed as part of the "DISTRHEAT—Digital Intelligent and Scalable conTrol for Renewables in HEAting neTworks" project, which received funding in the framework of the joint programming initiative ERA-Net Smart Energy Systems' focus initiative Integrated, Regional Energy Systems, with support from the European Union's Horizon 2020 research and innovation programme under grant agreement No 775970.

Conflicts of Interest: The authors declare no conflict of interest.

\section{Abbreviations}

$\begin{array}{ll}\text { CSA } & \text { Coordination and Support Action } \\ \text { DHC } & \text { District Heating and Cooling } \\ \text { DR } & \text { Demand Response } \\ \text { EU } & \text { European Union } \\ \text { FP } & \text { Framework Programme } \\ \text { IA } & \text { Innovation Action } \\ \text { ICT } & \text { Information and Communication Technologies } \\ \text { IoT } & \text { Internet-of-Things } \\ \text { LCA } & \text { Life Cycle Analysis } \\ \text { LCC } & \text { Life Cycle Cost } \\ \text { MPC } & \text { Model Predictive Control } \\ \text { RES } & \text { Renewable Energy Sources } \\ \text { RIA } & \text { Research and Innovation Action } \\ \text { SES } & \text { Smart Energy Systems } \\ \text { SET-Plan } & \text { Strategic Energy Technology Plan } \\ \text { SME } & \text { Small to Medium-sized Enterprise } \\ \text { TRL } & \text { Technology Readiness Level } \\ \text { WP } & \text { Work Package }\end{array}$

\section{Appendix A}

This appendix reports the general information and specific features of the 58 resulting projects. 
Table A1. General information of the selected projects funded by the Horizon 2020 Framework Programme.

\begin{tabular}{|c|c|c|c|c|c|c|c|}
\hline Project & Title & $\begin{array}{c}\text { Grant } \\
\text { Agreement }\end{array}$ & $\begin{array}{l}\text { Funding } \\
\text { Scheme }\end{array}$ & $\begin{array}{l}\text { Funding } \\
{[\boldsymbol{\epsilon}]}\end{array}$ & $\begin{array}{l}\text { Coordinator } \\
\text { Country }\end{array}$ & Start Date & End Date \\
\hline 4RinEU & $\begin{array}{l}\text { Robust and Reliable technology concepts and business models for } \\
\text { triggering deep Renovation of Residential buildings in EU }\end{array}$ & 723829 & IA & $4,627,954$ & Italy & 01/10/2016 & $30 / 06 / 2021$ \\
\hline CHESS-SETUP & $\begin{array}{l}\text { Combined Heat System by using Solar Energy and heaT pUmPs } \\
\text { Cool ways of using low grade Heat Sources from Cooling and Surplus }\end{array}$ & 680556 & IA & $3,703,706$ & Spain & 01/06/2016 & $31 / 05 / 2020$ \\
\hline Cool DH & $\begin{array}{c}\text { Heat for heating of Energy Efficient Buildings with new Low Temperature } \\
\text { District Heating (LTDH) Solutions }\end{array}$ & 767799 & IA & $5,291,186$ & Denmark & 01/10/2017 & $30 / 09 / 2021$ \\
\hline CoolHeating & $\begin{array}{c}\text { Market uptake of small modular renewable district heating and cooling } \\
\text { grids for communities }\end{array}$ & 691679 & CSA & $1,664,340$ & Germany & 01/01/2016 & $31 / 12 / 2018$ \\
\hline Create & Compact Retrofit Advanced Thermal Energy Storage & 680450 & RIA & $5,914,658$ & Netherlands & $01 / 10 / 2015$ & $30 / 06 / 2020$ \\
\hline$D R-B O B$ & Demand Response in Blocks of Buildings for Energy Systems & 696114 & IA & $5,136,770$ & $\begin{array}{l}\text { United } \\
\text { Kingdom }\end{array}$ & $01 / 03 / 2016$ & $31 / 08 / 2019$ \\
\hline$D R I v E$ & $\begin{array}{l}\text { Demand Response Integration tEchnologies: unlocking the demand } \\
\text { response potential in the distribution grid }\end{array}$ & 774431 & RIA & $3,955,259$ & Spain & $01 / 12 / 2017$ & $30 / 11 / 2020$ \\
\hline E2District & Energy Efficient Optimised District Heating and Cooling & 696009 & RIA & $1,999,849$ & Ireland & $01 / 02 / 2016$ & $31 / 07 / 2019$ \\
\hline EnergyMatching & $\begin{array}{l}\text { Adaptable and adaptive RES envelope solutions to maximise energy } \\
\text { harvesting and optimise EU building and district load matching }\end{array}$ & 768766 & IA & $6,994,120$ & Italy & 01/10/2017 & $31 / 03 / 2022$ \\
\hline ExcEED & $\begin{array}{l}\text { European Energy Efficient building district Database: from data to } \\
\text { information to knowledge }\end{array}$ & 723858 & CSA & 749,633 & Italy & $01 / 09 / 2016$ & $30 / 09 / 2019$ \\
\hline FLEXYNETS & $\begin{array}{l}\text { Fifth generation, Low temperature, high EXergY district heating and } \\
\text { cooling NETworkS }\end{array}$ & 649820 & RIA & $1,999,364$ & Italy & $01 / 07 / 2015$ & $31 / 12 / 2018$ \\
\hline FHP & $\begin{array}{l}\text { Flexible Heat and Power, Connecting heat and power networks by } \\
\text { harnessing the complexity in distributed thermal flexibility }\end{array}$ & 731231 & RIA & $3,823,606$ & Belgium & $01 / 11 / 2016$ & $31 / 10 / 2019$ \\
\hline HACKS & Heating And Cooling Know-how and Solutions & 845231 & CSA & $2,159,045$ & France & $01 / 09 / 2019$ & $31 / 08 / 2022$ \\
\hline H-DisNet & Intelligent Hybrid Thermo-Chemical District Networks & 695780 & RIA & $2,699,895$ & Belgium & $01 / 06 / 2016$ & $31 / 12 / 2019$ \\
\hline HEART & Holistic Energy and Architectural Retrofit Toolkit & 768921 & IA & $6,638,687$ & Italy & $01 / 10 / 2017$ & $30 / 09 / 2021$ \\
\hline Heat4Cool & $\begin{array}{l}\text { Smart building retrofitting complemented by solar assisted heat pumps } \\
\text { integrated within a self-correcting intelligent building energy management } \\
\text { system }\end{array}$ & 723925 & IA & $7,934,578$ & Italy & 03/10/2016 & 02/10/2020 \\
\hline HIT2GAP & $\begin{array}{l}\text { Highly Innovative building control Tools Tackling the energy performance } \\
\text { GAP }\end{array}$ & 680708 & IA & $7,914,590$ & France & $01 / 09 / 2015$ & $31 / 08 / 2019$ \\
\hline HOLISDER & $\begin{array}{l}\text { Integrating Real-Intelligence in Energy Management Systems enabling } \\
\text { Holistic Demand Response Optimization in Buildings and Districts }\end{array}$ & 768614 & IA & $5,052,547$ & Spain & $01 / 10 / 2017$ & $30 / 09 / 2020$ \\
\hline HotMaps & $\begin{array}{c}\text { Heating and Cooling: Open Source Tool for Mapping and Planning of } \\
\text { Energy Systems }\end{array}$ & 723677 & RIA & $2,996,870$ & Austria & 01/10/2016 & $30 / 09 / 2020$ \\
\hline
\end{tabular}


Table A1. Cont.

\begin{tabular}{|c|c|c|c|c|c|c|c|}
\hline Project & Title & $\begin{array}{c}\text { Grant } \\
\text { Agreement }\end{array}$ & $\begin{array}{l}\text { Funding } \\
\text { Scheme }\end{array}$ & $\begin{array}{l}\text { Funding } \\
{[\quad[\epsilon]}\end{array}$ & $\begin{array}{l}\text { Coordinator } \\
\text { Country }\end{array}$ & Start Date & End Date \\
\hline $\begin{array}{c}\text { HRE Heat } \\
\text { Roadmap Europe }\end{array}$ & $\begin{array}{l}\text { Building the knowledge, skills, and capacity required to enable new } \\
\text { policies and encourage new investments in the heating and cooling sector }\end{array}$ & 695989 & CSA & $2,113,482$ & Denmark & $01 / 03 / 2016$ & $28 / 02 / 2019$ \\
\hline InDeal & Innovative Technology for District Heating and Cooling & 696174 & RIA & $1,992,726$ & $\begin{array}{l}\text { United } \\
\text { Kingdom }\end{array}$ & $01 / 06 / 2016$ & $28 / 02 / 2019$ \\
\hline INDIGO & New generation of Intelligent Efficient District Cooling system & 696098 & RIA & $2,960,853$ & Spain & $01 / 03 / 2016$ & $30 / 09 / 2020$ \\
\hline InteGRIDy & $\begin{array}{l}\text { Integrated Smart GRID Cross-Functional Solutions for Optimized } \\
\text { Synergetic Energy Distribution, Utilization Storage Technologies }\end{array}$ & 731268 & IA & $15,840,275$ & Spain & $01 / 01 / 2017$ & $31 / 12 / 2020$ \\
\hline KeepWarm & $\begin{array}{c}\text { Improving the performance of district heating systems in Central and } \\
\text { Eastern Europe }\end{array}$ & 784966 & CSA & $2,098,497$ & Germany & $01 / 04 / 2018$ & $30 / 09 / 2020$ \\
\hline LOWUP & LOW valued energy sources UPgrading for buildings and industry users & 723930 & RIA & $4,086,245$ & Spain & $01 / 11 / 2016$ & $30 / 04 / 2020$ \\
\hline MAGNITUDE & $\begin{array}{l}\text { Bringing flexibility provided by multi energy carrier integration to a new } \\
\text { MAGNITUDE }\end{array}$ & 774309 & RIA & $3,999,058$ & France & $01 / 10 / 2017$ & $31 / 03 / 2021$ \\
\hline MAtchUP & $\begin{array}{c}\text { MAximizing the UPscaling and replication potential of high level urban } \\
\text { transformation strategies }\end{array}$ & 774477 & IA & $19,452,329$ & Spain & $01 / 10 / 2017$ & $30 / 09 / 2022$ \\
\hline MOBISTYLE & $\begin{array}{l}\text { MOtivating end-users Behavioral change by combined ICT based tools } \\
\text { and modular Information services on energy use, indoor environment, } \\
\text { health and lifestyle }\end{array}$ & 723032 & IA & $2,407,910$ & Netherlands & $01 / 10 / 2016$ & $30 / 06 / 2020$ \\
\hline MOEEBIUS & $\begin{array}{l}\text { Modeling and Optimization of Energy Efficiency in Buildings for Urban } \\
\text { Sustainability }\end{array}$ & 680517 & IA & $7,288,383$ & Spain & 01/11/2015 & $30 / 04 / 2019$ \\
\hline$M P C-: G T$ & $\begin{array}{c}\text { Model Predictive Control and Innovative System Integration of GEOTABS } \\
\text { in Hybrid Low Grade Thermal Energy Systems }\end{array}$ & 723649 & RIA & $4,263,701$ & Belgium & 01/09/2016 & $31 / 08 / 2020$ \\
\hline MUSE GRIDS & Multi Utilities Smart Energy GRIDS & 824441 & IA & 7,430,784 & Italy & $01 / 11 / 2018$ & $31 / 10 / 2022$ \\
\hline NewTREND & $\begin{array}{l}\text { New integrated methodology and Tools for Retrofit design towards a next } \\
\text { generation of Energy efficient and sustainable buildings and Districts }\end{array}$ & 680474 & IA & $5,732,388$ & $\begin{array}{l}\text { United } \\
\text { Kingdom }\end{array}$ & 01/09/2015 & $31 / 08 / 2018$ \\
\hline OptEEmAL & $\begin{array}{c}\text { Optimized Energy Efficient Design Platform for Refurbishment at District } \\
\text { Level }\end{array}$ & 680676 & IA & $4,748,859$ & Spain & 01/09/2015 & 28/02/2019 \\
\hline OPTi & Optimization of District Heating and Cooling systems & 649796 & RIA & $2,100,130$ & Sweden & $01 / 03 / 2015$ & $30 / 04 / 2018$ \\
\hline PENTAGON & $\begin{array}{c}\text { Unlocking European grid local flexibility through augmented energy } \\
\text { conversion capabilities at district level }\end{array}$ & 731125 & RIA & $4,437,834$ & $\begin{array}{l}\text { United } \\
\text { Kingdom }\end{array}$ & $01 / 12 / 2016$ & $30 / 11 / 2019$ \\
\hline Plan4Res & $\begin{array}{c}\text { Synergistic Approach of Multi-Energy Models for an European Optimal } \\
\text { Energy System Management Tool }\end{array}$ & 773897 & RIA & $3,905,060$ & France & 01/11/2017 & $31 / 10 / 2020$ \\
\hline
\end{tabular}


Table A1. Cont.

\begin{tabular}{|c|c|c|c|c|c|c|c|}
\hline Project & Title & $\begin{array}{c}\text { Grant } \\
\text { Agreement }\end{array}$ & $\begin{array}{l}\text { Funding } \\
\text { Scheme }\end{array}$ & $\begin{array}{l}\text { Funding } \\
{[€]}\end{array}$ & $\begin{array}{l}\text { Coordinator } \\
\text { Country }\end{array}$ & Start Date & End Date \\
\hline PLANET & $\begin{array}{c}\text { Planning and operational tools for optimising energy flows and synergies } \\
\text { between energy networks }\end{array}$ & 773839 & RIA & $3,999,695$ & Italy & $01 / 11 / 2017$ & $31 / 10 / 2020$ \\
\hline Planheat & $\begin{array}{l}\text { Integrated tool for empowering public authorities in the development of } \\
\text { sustainable plans for low carbon heating and cooling }\end{array}$ & 723757 & RIA & $2,999,400$ & Italy & 01/10/2016 & $31 / 01 / 2020$ \\
\hline progRESsHEAT & $\begin{array}{l}\text { Supporting the progress of renewable energies for heating and cooling in } \\
\text { the EU on a local level }\end{array}$ & 646573 & CSA & $1,728,305$ & Austria & 01/03/2015 & $31 / 10 / 2017$ \\
\hline RELaTED & REnewable Low TEmperature District & 768567 & IA & $4,755,475$ & Spain & $01 / 11 / 2017$ & $31 / 10 / 2021$ \\
\hline REMOURBAN & REgeneration MOdel for accelerating the smart URBAN transformation & 646511 & IA & $24,754,878$ & Spain & $01 / 01 / 2015$ & $30 / 06 / 2020$ \\
\hline RenoZEB & $\begin{array}{c}\text { Accelerating Energy renovation solution for Zero Energy buildings and } \\
\text { Neighbourhoods }\end{array}$ & 768718 & IA & $8,708,051$ & Spain & $01 / 10 / 2017$ & $30 / 09 / 2021$ \\
\hline RES4BUILD & Renewables for clean energy buildings in a future power system & 814865 & RIA & 4,999,702 & Germany & $01 / 05 / 2019$ & $30 / 04 / 2023$ \\
\hline RESPOND & $\begin{array}{c}\text { Integrated demand REsponse Solution towards energy POsitive } \\
\text { NeighbourhooDs }\end{array}$ & 768619 & IA & $3,693,615$ & Spain & $01 / 10 / 2017$ & $30 / 09 / 2020$ \\
\hline ReUseHeat & Recovery of Urban Excess Heat & 767429 & IA & $4,894,330$ & Sweden & $01 / 10 / 2017$ & $30 / 09 / 2021$ \\
\hline REWARDHeat & $\begin{array}{l}\text { Renewable and Waste Heat Recovery for Competitive District Heating and } \\
\text { Cooling Networks }\end{array}$ & 857811 & IA & $19,023,298$ & Italy & $01 / 10 / 2019$ & $30 / 09 / 2023$ \\
\hline SmartEnCity & Towards Smart Zero CO2 Cities across Europe & 691883 & IA & $31,874,538$ & Spain & $01 / 02 / 2016$ & $31 / 07 / 2021$ \\
\hline $\begin{array}{l}\text { SMARTER } \\
\text { TOGETHER }\end{array}$ & Smart and Inclusive Solutions for a Better Life in Urban Districts & 691876 & IA & $29,801,762$ & France & $01 / 02 / 2016$ & $31 / 01 / 2021$ \\
\hline SO WHAT & $\begin{array}{c}\text { Supporting new Opportunities for Waste Heat And cold valorisation } \\
\text { Towards EU decarbonization }\end{array}$ & 824441 & IA & $4,195,357$ & Italy & $01 / 06 / 2019$ & $31 / 05 / 2022$ \\
\hline Spine & Open source toolbox for modelling integrated energy systems & 774629 & RIA & $3,729,988$ & Finland & $01 / 10 / 2017$ & $30 / 09 / 2021$ \\
\hline STORM & Self-Organising Thermal Operational Resource Management & 649743 & RIA & $1,972,126$ & Belgium & $01 / 03 / 2015$ & $31 / 03 / 2019$ \\
\hline STORY & Added value of STORage in distribution sYstems & 646426 & IA & $15,353,840$ & Finland & $01 / 05 / 2015$ & $30 / 04 / 2020$ \\
\hline TEMPO & TEMPerature Optimisation for Low Temperature District Heating & 723649 & IA & $4,997,041$ & Belgium & $01 / 10 / 2017$ & $30 / 09 / 2021$ \\
\hline THERMOS & THermal Energy Resource Modelling and Optimisation System & 723636 & RIA & $2,902,480$ & $\begin{array}{l}\text { United } \\
\text { Kingdom }\end{array}$ & $01 / 10 / 2016$ & $30 / 06 / 2020$ \\
\hline THERMOSS & Building and district thermal retrofit and management solutions & 723562 & IA & $8,796,474$ & $\begin{array}{l}\text { United } \\
\text { Kingdom }\end{array}$ & $01 / 09 / 2016$ & $29 / 02 / 2020$ \\
\hline TOPAs & Tools for Continuous Building Performar & 676770 & IA & $6,139,296$ & Israel & $01 / 11 / 2015$ & $31 / 10 / 2018$ \\
\hline Upgrade $\mathrm{DH}$ & Upgrading the performance of district heating networks in Europe & 785014 & CSA & $1,999,667$ & Germany & $01 / 05 / 2018$ & $30 / 04 / 2021$ \\
\hline WEDISTRICT & $\begin{array}{c}\text { Smart and local reneWable Energy DISTRICT heating and cooling } \\
\text { solutions for sustainable living }\end{array}$ & 857801 & IA & $19,273,573$ & Spain & 01/10/2019 & $31 / 03 / 2023$ \\
\hline
\end{tabular}


Table A2. Relevant features of the selected projects funded by the Horizon 2020 Framework Programme.

\begin{tabular}{|c|c|c|c|c|c|c|c|c|c|c|c|c|c|c|c|c|c|c|c|c|c|c|c|c|}
\hline \multirow[b]{2}{*}{ Project } & \multicolumn{4}{|c|}{ Energy Vector } & \multicolumn{2}{|c|}{ Application } & \multicolumn{4}{|c|}{ Main Outcome } & \multicolumn{7}{|c|}{ Purpose } & \multicolumn{7}{|c|}{ Other Features } \\
\hline & 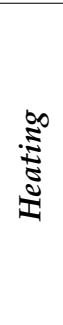 & $\begin{array}{l}\stackrel{\infty}{\Xi} \\
8 \\
0\end{array}$ & 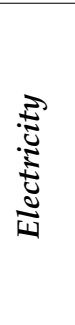 & $\stackrel{\mathscr{S}}{5}$ & 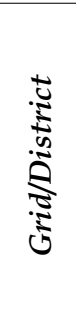 & 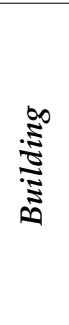 & 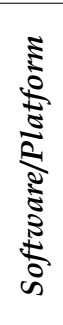 & 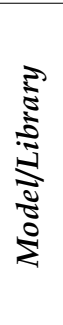 & 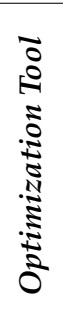 & 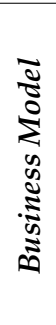 & 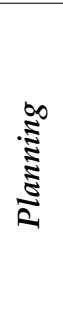 & 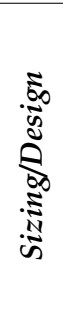 & 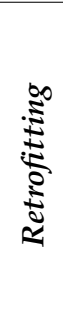 & 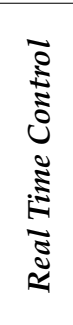 & 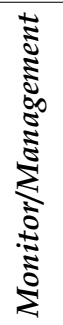 & 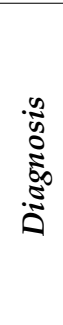 & $\underset{\sum}{\Sigma}$ & 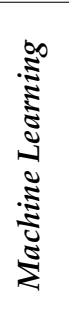 & 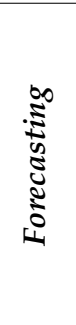 & 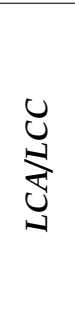 & 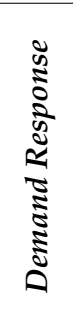 & 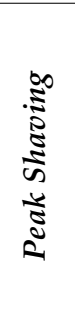 & $\frac{5}{5}$ & $\underset{\mathbb{2}}{\mathbb{2}}$ \\
\hline 4RinEU & $\checkmark$ & $\checkmark$ & & & & $\checkmark$ & $\checkmark$ & & & $\checkmark$ & & $\checkmark$ & $\checkmark$ & & & & & & & & & & & $\checkmark$ \\
\hline CHESS-SETUP & $\checkmark$ & $\checkmark$ & $\checkmark$ & & $\checkmark$ & $\checkmark$ & $\checkmark$ & & $\checkmark$ & $\checkmark$ & & $\checkmark$ & & & $\checkmark$ & & & & & & & & $\checkmark$ & $\checkmark$ \\
\hline Cool DH & $\checkmark$ & $\checkmark$ & & & $\checkmark$ & $\checkmark$ & & & & $\checkmark$ & & $\checkmark$ & $\checkmark$ & & & & & & & & & & & $\checkmark$ \\
\hline CoolHeating & $\checkmark$ & $\checkmark$ & & & $\checkmark$ & & & & & $\checkmark$ & & & & & & & & & & & & & & $\checkmark$ \\
\hline Create & $\checkmark$ & & & & & $\checkmark$ & & & & & & & & & & & & & & & & & $\checkmark$ & $\checkmark$ \\
\hline$D R-B O B$ & & & $\checkmark$ & & & $\checkmark$ & $\checkmark$ & & $\checkmark$ & $\checkmark$ & & & & $\checkmark$ & $\checkmark$ & & & & & & $\checkmark$ & & $\checkmark$ & \\
\hline DRIvE & & & $\checkmark$ & & $\checkmark$ & & $\checkmark$ & & & & & & & & $\checkmark$ & & & & $\checkmark$ & & $\checkmark$ & & & $\checkmark$ \\
\hline E2District & $\checkmark$ & $\checkmark$ & & & $\checkmark$ & $\checkmark$ & $\checkmark$ & $\checkmark$ & $\checkmark$ & $\checkmark$ & & & & $\checkmark$ & $\checkmark$ & $\checkmark$ & & $\checkmark$ & & $\checkmark$ & & & $\checkmark$ & $\checkmark$ \\
\hline EnergyMatching & $\checkmark$ & & $\checkmark$ & & $\checkmark$ & $\checkmark$ & & & $\checkmark$ & $\checkmark$ & & & & & $\checkmark$ & & & $\checkmark$ & & & & & & $\checkmark$ \\
\hline ExcEED & & & & & $\checkmark$ & $\checkmark$ & $\checkmark$ & & & $\checkmark$ & & & & & $\checkmark$ & & & & & & & & & \\
\hline FLEXYNETS & $\checkmark$ & $\checkmark$ & & & $\checkmark$ & & & $\checkmark$ & & $\checkmark$ & & & & $\checkmark$ & $\checkmark$ & & & & & & & & $\checkmark$ & $\checkmark$ \\
\hline$F H P$ & $\checkmark$ & & $\checkmark$ & & $\checkmark$ & $\checkmark$ & $\checkmark$ & $\checkmark$ & $\checkmark$ & $\checkmark$ & $\checkmark$ & & & $\checkmark$ & $\checkmark$ & & & & $\checkmark$ & & & & $\checkmark$ & $\checkmark$ \\
\hline HACKS & $\checkmark$ & $\checkmark$ & & & & $\checkmark$ & $\checkmark$ & & & & & & $\checkmark$ & & & & & & & & & & & \\
\hline H-DisNet & $\checkmark$ & $\checkmark$ & & & $\checkmark$ & & & $\checkmark$ & & $\checkmark$ & & & & $\checkmark$ & & & & $\checkmark$ & & & & & $\checkmark$ & $\checkmark$ \\
\hline HEART & $\checkmark$ & $\checkmark$ & $\checkmark$ & & & $\checkmark$ & $\checkmark$ & & & & $\checkmark$ & & $\checkmark$ & & $\checkmark$ & & & $\checkmark$ & $\checkmark$ & $\checkmark$ & & & & $\checkmark$ \\
\hline Heat4Cool & $\checkmark$ & $\checkmark$ & $\checkmark$ & & $\checkmark$ & $\checkmark$ & & & $\checkmark$ & $\checkmark$ & & $\checkmark$ & $\checkmark$ & $\checkmark$ & $\checkmark$ & & & $\checkmark$ & & & $\checkmark$ & & & $\checkmark$ \\
\hline HIT2GAP & $\checkmark$ & $\checkmark$ & $\checkmark$ & & & $\checkmark$ & $\checkmark$ & $\checkmark$ & & & & & & & $\checkmark$ & $\checkmark$ & & $\checkmark$ & $\checkmark$ & & & & & \\
\hline HOLISDER & $\checkmark$ & & $\checkmark$ & $\checkmark$ & $\checkmark$ & $\checkmark$ & & & $\checkmark$ & $\checkmark$ & & & & & $\checkmark$ & & & $\checkmark$ & & & $\checkmark$ & & $\checkmark$ & \\
\hline HotMaps & $\checkmark$ & $\checkmark$ & & & $\checkmark$ & & $\checkmark$ & $\checkmark$ & & & $\checkmark$ & & & & & & & & & & $\checkmark$ & & & $\checkmark$ \\
\hline HRE Heat Roadmap Europe & $\checkmark$ & $\checkmark$ & & & $\checkmark$ & & & $\checkmark$ & $\checkmark$ & $\checkmark$ & $\checkmark$ & & & & & & & & & & & & & $\checkmark$ \\
\hline InDeal & $\checkmark$ & $\checkmark$ & & & $\checkmark$ & $\checkmark$ & $\checkmark$ & & & & & & & & $\checkmark$ & & & $\checkmark$ & $\checkmark$ & & & & $\checkmark$ & $\checkmark$ \\
\hline INDIGO & & $\checkmark$ & & & $\checkmark$ & & $\checkmark$ & $\checkmark$ & $\checkmark$ & & $\checkmark$ & $\checkmark$ & & $\checkmark$ & $\checkmark$ & & $\checkmark$ & $\checkmark$ & $\checkmark$ & & & & & $\checkmark$ \\
\hline
\end{tabular}


Table A2. Cont.

\begin{tabular}{|c|c|c|c|c|c|c|c|c|c|c|c|c|c|c|c|c|c|c|c|c|c|c|c|c|}
\hline \multirow[b]{2}{*}{ Project } & \multicolumn{4}{|c|}{ Energy Vector } & \multicolumn{2}{|c|}{ Application } & \multicolumn{4}{|c|}{ Main Outcome } & \multicolumn{7}{|c|}{ Purpose } & \multicolumn{7}{|c|}{ Other Features } \\
\hline & 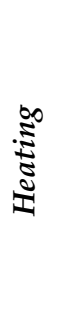 & $\frac{\mathfrak{0}}{\stackrel{\Xi}{\Xi}}$ & 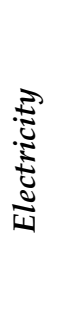 & $\stackrel{8}{0}$ & 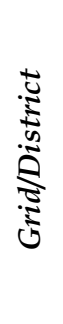 & 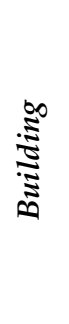 & 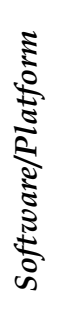 & 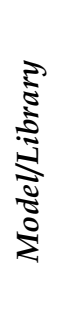 & 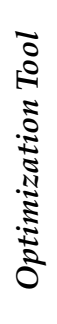 & 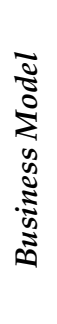 & 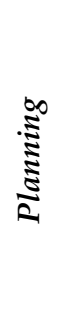 & 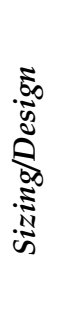 & 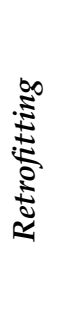 & 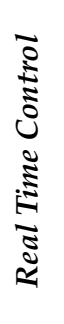 & 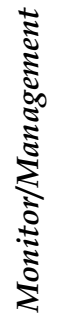 & 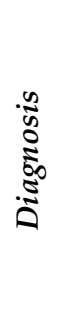 & $\underset{z}{\Sigma}$ & 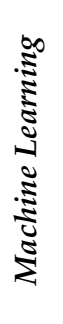 & 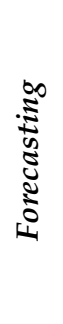 & 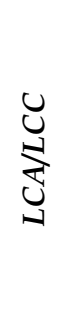 & 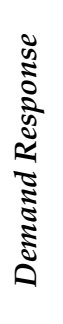 & 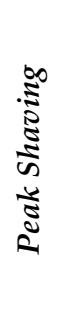 & $\frac{5}{5}$ & $\underset{\mathbb{2}}{\mathbb{2}}$ \\
\hline InteGRIDy & & & $\checkmark$ & & $\checkmark$ & & $\checkmark$ & & $\checkmark$ & $\checkmark$ & $\checkmark$ & & & & $\checkmark$ & & & & $\checkmark$ & & $\checkmark$ & & $\checkmark$ & $\checkmark$ \\
\hline KeepWarm & $\checkmark$ & $\checkmark$ & & & $\checkmark$ & & & & & $\checkmark$ & & & $\checkmark$ & & $\checkmark$ & & & & & & & & & $\checkmark$ \\
\hline LOWUP & $\checkmark$ & $\checkmark$ & & & & $\checkmark$ & & & & & & $\checkmark$ & & $\checkmark$ & & & & & & & & & $\checkmark$ & $\checkmark$ \\
\hline MAGNITUDE & $\checkmark$ & $\checkmark$ & $\checkmark$ & $\checkmark$ & $\checkmark$ & & $\checkmark$ & $\checkmark$ & $\checkmark$ & $\checkmark$ & & & & $\checkmark$ & $\checkmark$ & & & & $\checkmark$ & & & & & $\checkmark$ \\
\hline MAtchUP & $\checkmark$ & & $\checkmark$ & & $\checkmark$ & $\checkmark$ & & & & $\checkmark$ & $\checkmark$ & & & $\checkmark$ & $\checkmark$ & $\checkmark$ & & & & & & & $\checkmark$ & $\checkmark$ \\
\hline MOBISTYLE & & & & & & $\checkmark$ & $\checkmark$ & & & $\checkmark$ & & & & & $\checkmark$ & & & $\checkmark$ & & & & & & \\
\hline MOEEBIUS & $\checkmark$ & & $\checkmark$ & & $\checkmark$ & $\checkmark$ & & $\checkmark$ & $\checkmark$ & $\checkmark$ & & & $\checkmark$ & $\checkmark$ & & $\checkmark$ & & & $\checkmark$ & $\checkmark$ & & $\checkmark$ & & $\checkmark$ \\
\hline MPC-: GT & $\checkmark$ & & & & & $\checkmark$ & & $\checkmark$ & $\checkmark$ & & & $\checkmark$ & & $\checkmark$ & & & $\checkmark$ & & & & & & & $\checkmark$ \\
\hline MUSE GRIDS & $\checkmark$ & $\checkmark$ & $\checkmark$ & $\checkmark$ & $\checkmark$ & & & & $\checkmark$ & & $\checkmark$ & & & $\checkmark$ & $\checkmark$ & & & $\checkmark$ & & & & & $\checkmark$ & $\checkmark$ \\
\hline NewTREND & & & & & $\checkmark$ & $\checkmark$ & $\checkmark$ & $\checkmark$ & & $\checkmark$ & & $\checkmark$ & $\checkmark$ & & & & & & & $\checkmark$ & & & & $\checkmark$ \\
\hline OptEEmAL & $\checkmark$ & $\checkmark$ & & & $\checkmark$ & & $\checkmark$ & & $\checkmark$ & & & $\checkmark$ & $\checkmark$ & & & & & $\checkmark$ & & $\checkmark$ & & & & \\
\hline OPTi & $\checkmark$ & $\checkmark$ & & & $\checkmark$ & & $\checkmark$ & $\checkmark$ & $\checkmark$ & & & & & $\checkmark$ & & & $\checkmark$ & $\checkmark$ & $\checkmark$ & & $\checkmark$ & $\checkmark$ & & \\
\hline PENTAGON & $\checkmark$ & $\checkmark$ & $\checkmark$ & $\checkmark$ & $\checkmark$ & $\checkmark$ & $\checkmark$ & & & & & & & & $\checkmark$ & & & $\checkmark$ & & & & & $\checkmark$ & $\checkmark$ \\
\hline Plan4Res & $\checkmark$ & $\checkmark$ & $\checkmark$ & $\checkmark$ & $\checkmark$ & & $\checkmark$ & $\checkmark$ & $\checkmark$ & & $\checkmark$ & & & & $\checkmark$ & & & & & & & & & $\checkmark$ \\
\hline PLANET & $\checkmark$ & $\checkmark$ & $\checkmark$ & $\checkmark$ & $\checkmark$ & & $\checkmark$ & $\checkmark$ & $\checkmark$ & $\checkmark$ & $\checkmark$ & & & & $\checkmark$ & & & & & & & & $\checkmark$ & $\checkmark$ \\
\hline Planheat & $\checkmark$ & $\checkmark$ & & & $\checkmark$ & & $\checkmark$ & & & & $\checkmark$ & & & & & & & & $\checkmark$ & & & & & $\checkmark$ \\
\hline progRESsHEAT & $\checkmark$ & $\checkmark$ & $\checkmark$ & & $\checkmark$ & & & & & & $\checkmark$ & & & & & & & & & & & & & $\checkmark$ \\
\hline RELaTED & $\checkmark$ & & & & $\checkmark$ & & & & & & & & & & $\checkmark$ & & & & & & & & & $\checkmark$ \\
\hline REMOURBAN & $\checkmark$ & & $\checkmark$ & & $\checkmark$ & $\checkmark$ & $\checkmark$ & & & $\checkmark$ & $\checkmark$ & & $\checkmark$ & & $\checkmark$ & & & & & & & & & $\checkmark$ \\
\hline RenoZEB & $\checkmark$ & & $\checkmark$ & & & $\checkmark$ & $\checkmark$ & & & & & & $\checkmark$ & $\checkmark$ & $\checkmark$ & & & $\checkmark$ & & & & & & \\
\hline RES4BUILD & $\checkmark$ & & $\checkmark$ & & & $\checkmark$ & & $\checkmark$ & & $\checkmark$ & & $\checkmark$ & & & $\checkmark$ & & & & & $\checkmark$ & & & $\checkmark$ & $\checkmark$ \\
\hline RESPOND & $\checkmark$ & & $\checkmark$ & & $\checkmark$ & $\checkmark$ & & & $\checkmark$ & & & & & $\checkmark$ & $\checkmark$ & & & & & & $\checkmark$ & & & \\
\hline ReUseHeat & $\checkmark$ & $\checkmark$ & & & $\checkmark$ & & & & & $\checkmark$ & $\checkmark$ & $\checkmark$ & & & & & & & & & & & & \\
\hline REWARDHeat & $\checkmark$ & & & & $\checkmark$ & & & & & $\checkmark$ & & & & $\checkmark$ & & & & & & & & & $\checkmark$ & $\checkmark$ \\
\hline
\end{tabular}


Table A2. Cont.

\begin{tabular}{|c|c|c|c|c|c|c|c|c|c|c|c|c|c|c|c|c|c|c|c|c|c|c|c|c|}
\hline \multirow[b]{2}{*}{ Project } & \multicolumn{4}{|c|}{ Energy Vector } & \multicolumn{2}{|c|}{ Application } & \multicolumn{4}{|c|}{ Main Outcome } & \multicolumn{7}{|c|}{ Purpose } & \multicolumn{7}{|c|}{ Other Features } \\
\hline & 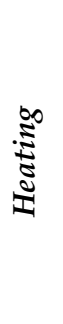 & $\frac{0}{\stackrel{\Xi}{\Xi}}$ & 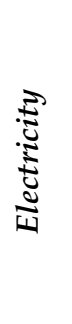 & $\stackrel{8}{8}$ & 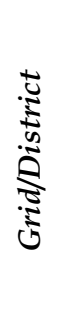 & 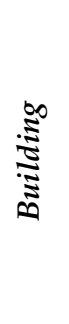 & 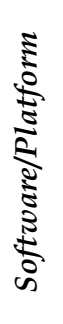 & 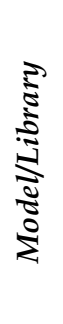 & 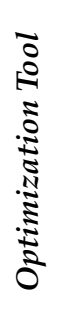 & 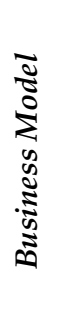 & 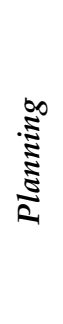 & 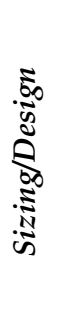 & 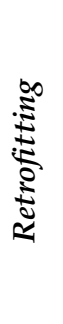 & 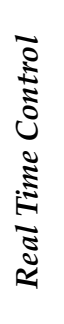 & 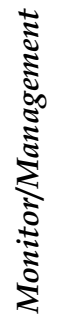 & 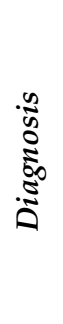 & $\sum_{z}^{u}$ & 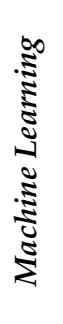 & 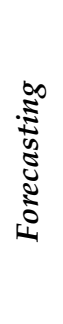 & 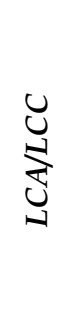 & 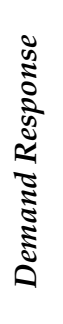 & 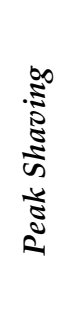 & $\frac{5}{5}$ & 勻 \\
\hline SmartEnCity & $\checkmark$ & $\checkmark$ & $\checkmark$ & $\checkmark$ & $\checkmark$ & $\checkmark$ & & & & $\checkmark$ & $\checkmark$ & & $\checkmark$ & & $\checkmark$ & $\checkmark$ & & & & & & & & $\checkmark$ \\
\hline SMARTER TOGETHER & $\checkmark$ & & $\checkmark$ & & $\checkmark$ & $\checkmark$ & $\checkmark$ & & & $\checkmark$ & & $\checkmark$ & $\checkmark$ & & & & & $\checkmark$ & & & & & & $\checkmark$ \\
\hline SO WHAT & $\checkmark$ & $\checkmark$ & & & $\checkmark$ & & $\checkmark$ & & & & & & & & & & & & $\checkmark$ & & & & $\checkmark$ & $\checkmark$ \\
\hline Spine & & & & & $\checkmark$ & & $\checkmark$ & $\checkmark$ & $\checkmark$ & & $\checkmark$ & & & & & & & & & & & & & \\
\hline STORM & $\checkmark$ & $\checkmark$ & & & $\checkmark$ & $\checkmark$ & & $\checkmark$ & $\checkmark$ & & & & & $\checkmark$ & $\checkmark$ & & & $\checkmark$ & $\checkmark$ & & & $\checkmark$ & $\checkmark$ & $\checkmark$ \\
\hline STORY & $\checkmark$ & & $\checkmark$ & & $\checkmark$ & & & $\checkmark$ & & $\checkmark$ & & & & $\checkmark$ & $\checkmark$ & & & & $\checkmark$ & & & & $\checkmark$ & \\
\hline TEMPO & $\checkmark$ & & & & $\checkmark$ & $\checkmark$ & $\checkmark$ & & $\checkmark$ & $\checkmark$ & & $\checkmark$ & $\checkmark$ & & $\checkmark$ & $\checkmark$ & & & & & & & & $\checkmark$ \\
\hline THERMOS & $\checkmark$ & & & & $\checkmark$ & & $\checkmark$ & $\checkmark$ & $\checkmark$ & & $\checkmark$ & & & & $\checkmark$ & & & & & & & & & \\
\hline THERMOSS & $\checkmark$ & $\checkmark$ & & & $\checkmark$ & $\checkmark$ & $\checkmark$ & & & & & & $\checkmark$ & & $\checkmark$ & & & & & & & & & \\
\hline TOPAs & $\checkmark$ & & & & & $\checkmark$ & $\checkmark$ & $\checkmark$ & $\checkmark$ & & & & & $\checkmark$ & $\checkmark$ & $\checkmark$ & $\checkmark$ & $\checkmark$ & & & & & & \\
\hline Upgrade $\mathrm{DH}$ & $\checkmark$ & & & & $\checkmark$ & & & & & $\checkmark$ & & & $\checkmark$ & & & $\checkmark$ & & & & & & & & $\checkmark$ \\
\hline WEDISTRICT & $\checkmark$ & $\checkmark$ & & & $\checkmark$ & & $\checkmark$ & & & & & $\checkmark$ & $\checkmark$ & & $\checkmark$ & & & & & & & & $\checkmark$ & $\checkmark$ \\
\hline
\end{tabular}




\section{References}

1. Colombo, L.A.; Pansera, M.; Owen, R. The discourse of eco-innovation in the European Union: An analysis of the Eco-Innovation Action Plan and Horizon 2020. J. Clean. Prod. 2019, 214, 653-665. [CrossRef]

2. Lund, H.; Werner, S.; Wiltshire, R.; Svendsen, S.; Thorsen, J.E.; Hvelplund, F.; Mathiesen, B.V. 4th Generation District Heating (4GDH): Integrating smart thermal grids into future sustainable energy systems. Energy 2014, 68, 1-11. [CrossRef]

3. Bertelsen, N.; Mathiesen, B.V. EU-28 residential heat supply and consumption: Historical development and status. Energies 2020,13, 1894. [CrossRef]

4. Lund, H.; Østergaard, P.A.; Connolly, D.; Mathiesen, B.V. Smart energy and smart energy systems. Energy 2017, 137, 556-565. [CrossRef]

5. Hossein Motlagh, N.; Mohammadrezaei, M.; Hunt, J.; Zakeri, B. Internet of Things (IoT) and the energy sector. Energies 2020, 13, 494. [CrossRef]

6. Lund, H.; Østergaard, P.A.; Chang, M.; Werner, S.; Svendsen, S.; Sorknæs, P.; Thorsen, J.E.; Hvelplund, F.; Mortensen, B.O.G.; Mathiesen, B.V.; et al. The status of 4th generation district heating: Research and results. Energy 2018, 164, 147-159. [CrossRef]

7. Yigitcanlar, T.; Desouza, K.C.; Butler, L.; Roozkhosh, F. Contributions and risks of Artificial Intelligence (AI) in building smarter cities: Insights from a systematic review of the literature. Energies 2020, 13, 1473. [CrossRef]

8. Runge, J.; Zmeureanu, R. Forecasting energy use in buildings using artificial neural networks: A review. Energies 2019, 12, 3254. [CrossRef]

9. Corlu, C.G.; de la Torre, R.; Serrano-Hernandez, A.; Juan, A.A.; Faulin, J. Optimizing energy consumption in transportation: Literature review, insights, and research opportunities. Energies 2020, 13, 1115. [CrossRef]

10. Espín-Sarzosa, D.; Palma-Behnke, R.; Núñez-Mata, O. Energy management systems for microgrids: Main existing trends in centralized control architectures. Energies 2020, 13, 547. [CrossRef]

11. European Commission. Overview of the Support Activities and Projects of the European Union on Energy Efficiency and Renewable Energy in the Heating and Cooling Sector-Horizon 2020, Framework Programme 7 and Intelligent Energy Europe Programmes of the European Union; Publication Office of the European Union: Luxembourg, 2016. [CrossRef]

12. Carlsson, J.; Chondrogiannis, S.; Kapetaki, Z.; Kougias, I.; Jakubcionis, M.; Magagna, D.; Miranda Barbosa, E.; Nijs, W.; O'Connell, A.; Padella, M.; et al. Low Carbon Energy Observatory—Clean Energy Technologies Synergies and Issues; Publication Office of the European Union: Luxembourg, 2020. [CrossRef]

13. Jellema, J.; Mulder, H.A.J. Public engagement in energy research. Energies 2016, 9, 125. [CrossRef]

14. Communication from the Commission to the Council, the European Parliament, the European Economic and Social Committee and the Committee of the Regions-A European Strategic Energy Technology Plan (Set-Plan)—Towards a Low Carbon Future. Brussels, 22.11.2007. Available online: https://eur-lex.europa.eu/ legal-content/EN/TXT/?uri=CELEX:52007DC0723\#document1 (accessed on 16 April 2020).

15. European Commission, Directorate-General for Energy. Clean Energy for All Europeans; Publication Office of the European Union: Luxembourg, 2019. [CrossRef]

16. European Commission, Directorate-General for Research and Innovation. The Strategic Energy Technology Plan-At the Heart of Energy Research and Innovation in Europe; 2007-2017 SET-Plan 10th Anniversary; Publication Office of the European Union: Luxembourg, 2018. [CrossRef]

17. United Nations Treaty Collection-Paris Agreement, Chapter XXVII-Environment. Available online: https://treaties.un.org/pages/ViewDetails.aspx?src=TREATY\&mtdsg_no=XXVII-7-d\&chapter=27\& clang=_en (accessed on 16 April 2020).

18. Celsius Wiki-A District Energy Knowledge Resource. Available online: http://toolbox.celsiuscity.eu/index. php/Main_Page (accessed on 16 April 2020).

19. Gómez-Romero, J.; Molina-Solana, M.; Ros, M.; Ruiz, M.D.; Martin-Bautista, M.J. Comfort as a service: A new paradigm for residential environmental quality control. Sustainability 2018, 10, 3053. [CrossRef]

20. Tuominen, P.; Stenlund, O.; Marguerite, C.; Pardo-Garcia, N.; Grahn, E.; Huvilinna, J.; Iglar, B. Cityopt Planning tool for energy efficient cities. Int. J. Sustain. Dev. Plan. 2017, 12, 570-579. [CrossRef]

21. Dahl, M.; Brun, A.; Kirsebom, O.S.; Andresen, G.B. Improving short-term heat load forecasts with calendar and holiday data. Energies 2018, 11, 1678. [CrossRef] 
22. European Commission, Directorate-General for Research and Innovation. Horizon 2020 in Brief-The EU Framework Programme for Research and Innovation; Publication Office of the European Union: Luxembourg, 2014. [CrossRef]

23. European Commission, Horizon 2020 Sections. Available online: https://ec.europa.eu/programmes/ horizon2020/en/h2020-sections (accessed on 16 April 2020).

24. European Commission, Funding and Tender Opportunities. Call EE-13-2015-Technology for District Heating and Cooling. Available online: https://ec.europa.eu/info/funding-tenders/opportunities/portal/ screen/opportunities/topic-details/ee-13-2015 (accessed on 16 April 2020).

25. European Commission, Funding and Tender Opportunities. Call LC-SC3-RES-8-2019-Combining Renewable Technologies for a Renewable District Heating and/or Cooling System. Available online: https://ec.europa.eu/info/funding-tenders/opportunities/portal/screen/opportunities/topic-details/ lc-sc3-res-8-2019 (accessed on 16 April 2020).

26. European Commission, Horizon Europe-The Next Research and Innovation Framework Programme. Available online: https://ec.europa.eu/info/horizon-europe-next-research-and-innovation-frameworkprogramme_en (accessed on 16 April 2020).

27. European Commission. Annexes to the Proposal for a Decision of the European Parliament and of the Council on Establishing the Specific Programme Implementing Horizon Europe-The Framework Programme for Research and Innovation. Annex 5-Horizon Europe Cluster 5: Climate, Energy and Mobility. Brussels, 7.6.18. Available online: https://ec.europa.eu/research/pdf/horizon-europe/annex-5.pdf (accessed on 16 April 2020).

28. Moseley, P. EU support for innovation and market uptake in smart buildings under the horizon 2020 framework programme. Buildings 2017, 7, 105. [CrossRef]

29. Longo, D.; Olivieri, G.; Roversi, R.; Turci, G.; Turillazzi, B. Energy poverty and protection of vulnerable consumers. Overview of the EU funding programs FP7 and H2020 and future trends in horizon Europe. Energies 2020, 13, 1030. [CrossRef]

30. Clerici Maestosi, P.; Civiero, P.; Massa, G. European Union funding research devlopment and innovation projects on smart cities: The state of the art in 2019. Int. J. Sustain. Energy Plan. Manag. 2019, 24, 7-20. [CrossRef]

31. European Commission, CORDIS, EU Research Results. Available online: www.cordis.europa.eu/en (accessed on 16 April 2020).

32. Saletti, C.; Gambarotta, A.; Morini, M. Development, analysis and application of a predictive controller to a small-scale district heating system. Appl. Therm. Eng. 2020. [CrossRef]

33. Suryanarayana, G.; Lago, J.; Geysen, D.; Aleksiejuk, P.; Johansson, C. Thermal load forecasting in district heating networks using deep learning and advanced feature selection methods. Energy 2018, 157, 141-149. [CrossRef]

34. Rämä, M.; Klobut, K. Tools for planning energy efficient district systems. Proceedings 2018, 2, 1132. [CrossRef]

35. Månsson, S.; Johansson Kallioniemi, P.O.; Thern, M.; Van Oevelen, T.; Sernhed, K. Faults in district heating customer installations and ways to approach them: Experiences from Swedish utilities. Energy 2019, 180, 163-174. [CrossRef]

36. Loureiro, T.; Sterling, R.; Vinyals, M. Demand response integration tEchnologies: Unlocking the demand response potential in the distribution grid. Proceedings 2018, 2, 1129. [CrossRef]

37. Blanke, J.; Beder, C.; Twomey, E.; Ozdemir, S.A.; Klepal, M. E2District: Behaviour demand response. Proceedings 2017, 1, 691. [CrossRef]

38. Del Hoyo Arce, I.; Herrero López, S.; López Perez, S.; Rämä, M.; Klobut, K.; Febres, J.A. Models for fast modelling of district heating and cooling networks. Renew. Sustain. Energy Rev. 2018, 82, 1863-1873. [CrossRef]

39. OPTi Project Website. Available online: http://www.opti2020.eu/ (accessed on 16 April 2020).

40. Walker, S.S.W.; Lombardi, W.; Lesecq, S.; Roshany-Yamchi, S. Application of distributed model predictive approaches to temperature and $\mathrm{CO}_{2}$ concentration control in buildings. IFAC Pap. 2017, 50, 2589-2594. [CrossRef]

41. FLEXYNETS Project Website. Available online: http://www.flexynets.eu/en/ (accessed on 16 April 2020).

42. Neirotti, F.; Noussan, M.; Riverso, S.; Manganini, G. Analysis of different strategies for lowering the operation temperature in existing district heating networks. Energies 2019, 12, 321. [CrossRef] 
43. European Commission. Analysis of ERA-NET Cofund Actions under Horizon 2020; Final Report of the Expert Group; Publication Office of the European Union: Luxembourg, 2016. [CrossRef]

44. ERA-Net Smart Energy Systems Website. Approved Projects and Their Outcomes. Available online: https://www.eranet-smartenergysystems.eu/Projects (accessed on 16 April 2020).

45. Reinders, A.; Übermasser, S.; van Sark, W.; Gercek, C.; Schram, W.; Obinna, U.; Lehfuss, F.; van Mierlo, B.; Robledo, C.; van Wijk, A. An exploration of the three-layer model including stakeholders, markets and technologies for assessments of residential smart grids. Appl. Sci. 2018, 8, 2363. [CrossRef]

46. ReFlex Project Website. Available online: http://reflex-smartgrid.eu/ (accessed on 16 April 2020).

47. DISTRHEAT Project Website. Available online: https://www.distrheat.eu/ (accessed on 16 April 2020).

48. International Energy Agency (IEA). Global Energy Review 2020-The Impacts of the COVID-19 Crisis on Global Energy Demand and $\mathrm{CO}_{2}$ Emissions. Flagship Report April 2020. Available online: https: //www.iea.org/reports/global-energy-review-2020 (accessed on 17 May 2020).

49. ETIP SNET. ETIP SNET R\&I Implementation Plan 2021-2024. 2020. Available online: https://www.etipsnet.eu/wp-content/uploads/2020/05/Implementation-Plan-2021-2024_WEB_Single-Page.pdf (accessed on 17 May 2020).

50. DHC + Technology Platform c/o Euroheat \& Power. Digital Roadmap for District Heating and Cooling. Version 2, July 2019. Available online: https://www.euroheat.org/wp-content/uploads/2018/05/DigitalRoadmap_final.pdf (accessed on 17 May 2020).

51. RHC - Renewable Heating and Cooling-European Technology and Innovation Platform. 2050 Vision for 100\% Renewable Heating and Cooling in Europe. 2019. Available online: https://www.euroheat.org/wpcontent/uploads/2019/10/RHC-VISION-2050-WEB.pdf (accessed on 17 May 2020).

52. European Commission, Funding and Tender Opportunities. Call LC-SC3-SCC-2-2020-Positive Energy Districts and Neighbourhoods for Urban Energy Transitions. Available online: https://ec.europa.eu/ info/funding-tenders/opportunities/portal/screen/opportunities/topic-details/lc-sc3-scc-2-2020 (accessed on 17 May 2020).

(C) 2020 by the authors. Licensee MDPI, Basel, Switzerland. This article is an open access article distributed under the terms and conditions of the Creative Commons Attribution (CC BY) license (http://creativecommons.org/licenses/by/4.0/). 